\title{
Article \\ Quantification of Measurement and Model Effects in Monopile Foundation Scour Protection Experiments
}

\author{
Minghao $\mathrm{Wu}^{1, *}{ }^{\mathbb{D}}$, Leen De $\left.\operatorname{Vos}^{2}{ }^{(}\right)$, Carlos Emilio Arboleda Chavez ${ }^{1}\left(\mathbb{D}\right.$, Vasiliki Stratigaki ${ }^{1}(\mathbb{D}$, \\ Maximilian Streicher ${ }^{1}$ (D) and Peter Troch ${ }^{1}$ (D) \\ 1 Department of Civil Engineering, Ghent University, 9052 Zwijnaarde, Belgium; \\ Carlosemilio.Arboledachavez@UGent.be (C.E.A.C.); Vicky.Stratigaki@UGent.be (V.S.); \\ Maximilian.Streicher@UGent.be (M.S.); Peter.Troch@UGent.be (P.T.) \\ 2 Department of Mobility and Public Works, Geotechnics Division, Flemish Government, \\ 9052 Zwijnaarde, Belgium; leen.devos@mow.vlaanderen.be \\ * Correspondence: Minghao.Wu@UGent.be
}

Citation: Wu, M.; De Vos, L.;

Arboleda Chavez, C.E.; Stratigaki, V.; Streicher, M.; Troch, P. Quantification of Measurement and Model Effects in Monopile Foundation Scour Protection Experiments. J. Mar. Sci. Eng. 2021, 9, 585. https://doi.org/ $10.3390 /$ jmse 9060585

Academic Editor: Cameron Johnstone

Received: 30 April 2021

Accepted: 19 May 2021

Published: 28 May 2021

Publisher's Note: MDPI stays neutra with regard to jurisdictional claims in published maps and institutional affiliations.

Copyright: (C) 2021 by the authors. Licensee MDPI, Basel, Switzerland. This article is an open access article distributed under the terms and conditions of the Creative Commons Attribution (CC BY) license (https:// creativecommons.org/licenses/by/ $4.0 /$ )

\begin{abstract}
The present work introduces an analysis of the measurement and model effects that exist in monopile scour protection experiments with repeated small scale tests. The damage erosion is calculated using the three dimensional global damage number $S_{3 D}$ and subarea damage number $S_{3 D, i}$. Results show that the standard deviation of the global damage number $\sigma\left(S_{3 D}\right)=0.257$ and is approximately $20 \%$ of the mean $S_{3 D}$, and the standard deviation of the subarea damage number $\sigma\left(S_{3 D, i}\right)=0.42$ which can be up to $33 \%$ of the mean $S_{3 D}$. The irreproducible maximum wave height, chaotic flow field and non-repeatable armour layer construction are regarded as the main reasons for the occurrence of strong model effects. The measurement effects are limited to $\sigma\left(S_{3 D}\right)=0.039$ and $\sigma\left(S_{3 D, i}\right)=0.083$, which are minor compared to the model effects.
\end{abstract}

Keywords: monopile foundation; scour protection; experiments; measurement effects; model effects; damage number

\section{Introduction}

The expanding offshore wind energy industry requires more cost competitive solutions for the offshore wind turbines (OWTs) and their foundations. In shallow and intermediate water conditions, the monopile foundation is the most favoured one for OWTs due to its low complexity in manufacturing, installation and operation [1]. Exposed to the harsh sea environment of current and waves, the monopile foundations are protected with a layer of armour materials against the scouring around the monopile structure. Such a scour protection layer is mostly built with riprap, and can also be installed using concrete mattress and geotextile sand container [2,3]. Alternatively, flow-altering countermeasures, such as integrated tidal current turbine and anti-scour collar, are also promising engineering solutions for scour protection [4-6]. With the rise of new generation monopile OWTs, reducing the engineering cost and enhancing the functionality of the scour protection become significant issues.

The research of the riprap scour protection of an OWT foundation begins on the basis of the scour mechanism. Many studies have been made in river engineering regarding the scour around bridge piles in fluvial currents [7-9] as well as the design of the scour protection layer of bridge piles [10,11]. As for the piles at sea, the wave induced oscillatory flow combined with currents makes the scour problem different from that in a river environment and the Keulegan-Carpenter number (KC) becomes a governing factor. Such mechanism of scour around piles in ocean environment is introduced in [12]. Empirical formulas to estimate the maximum scour depth around a cylindrical pile are applied in OWT design [13]. Regarding the performance of riprap scour protection around an OWT foundation, the conduct of laboratory experiments is the most adopted way to tackle 
with the three failure modes: (1) erosion damage, (2) winnowing, and (3) edge scour. Towards the failure mode (1), Den Boon et al. (2004) [14] carried out an experimental study and suggests to use a STAB parameter to describe the erosion failure of a monopile scour protection. The STAB parameter is defined as a ratio between the maximum and critical Shields parameters. De Vos et al. $(2001,2002)[15,16]$ propose empirical formulas to estimate the erosion of the scour protection layer from both static and dynamic perspectives via a 1:50 laboratory scale model test. Other relevant works are seen in [17-22]. Failure modes (2) and (3) are addressed in [23-26]. In addition to the laboratory experiments, field surveys provide more details about how monopile scour protection behaves in real life sea conditions, such field data is available in [27]. Furthermore, the design of the scour protection layer has been recently discussed by $[2,28]$.

Various experiments of monopile scour protection solutions have revealed the key mechanisms of the erosion damage failure (failure mode (1) as introduced above) of the scour protection. When flow passes the bottom fixed pile, the fluid velocity accelerates, the streamline will separate and form a horseshoe vortex in front of the pile and a lee-wake vortex downstream the pile [12]. The local fluid velocity amplifies and the bed shear stress acting on the armour stone might exceed the critical value for its threshold of motion. The main difference between offshore pile and river bridge pile is that the formation of horseshoe vortex and vortex shedding around an offshore pile can be intermittent and multidirectional due to the action of wave orbital velocity, which results in a different shear stress distribution over the scour protection around an offshore pile. In addition, the oscillatory wave flow introduces a backfilling of materials to the bed erosion area near the pile [29].

For most of the laboratory experimental studies, small scale hydraulic models are employed. A few large scale wave flume laboratory experiments are also reported recently in $[20,30,31]$. However, the accuracy of reproducing test conditions in laboratory experiments can cause significant differences between scaled model and prototype. Kortenhaus et al. (2005) [32] attribute the sources of such differences into measurement effects, model effects and scale effects. These effects constitute the experimental uncertainties in a model test in ocean engineering [33], which are essential for evaluating the quality of experimental results [34].

- Measurement effects

The measurement effects are caused by the different configurations of the measurement system, which refer to error or inaccuracy of the measurement system due to the resolution of data sampling, the location of probes and the quality of measurement. In monopile scour protection tests, the measurement effects are mainly caused by the accuracy of wave gauges, velocity meters, distance sensors, bed profile scanner or pressure gauges. Despite the accuracy information provided in the specification of the instrument, the measurement effects can also be caused by calibration induced errors, human manipulation and environment condition variation, such as light, humidity, temperature, etc. It is sometimes necessary to use a statistic analysis method and repeated measurements to check the applicability and the uncertainty level of using such instruments [32]. According to [35,36], the set-up and application of the bed profile scanner is considered to be the major source of the measurement effects in monopile scour protection experiments.

- Model effects

The model effects originate from the incorrect reproduction of the prototype situation in the laboratory facility. They are significantly associated with the reliability of the experimental results based on a single test. In experiments for modelling monopile scour protections, the model effects are mainly caused by wave and current generation, armour layer construction, sediment and pile construction. When the experiments are carried out in different wave flumes, model effects may also be introduced by different flume side walls, wave paddles and wave absorption systems. In comparison to the scale effects, the model effects often have less impact, but can sometimes 
be considerably high, especially when there is observed non-repeatability of the experimental conditions. For example, (i) due to the presence of turbulence and interactions between waves and current, the instantaneous pressure and velocity distributions around the pile are different; (ii) the impossibility of building an identical armour layer makes the results of one test deviating from the results from a repeated test. Regarding these problems, the present study refers to [32] who suggest to apply repeated tests, such as re-constructing the armour layer several times, in order to quantify model effects in small scale tests.

- $\quad$ Scale effects

The scale effects are induced by the incorrect reproduction of prototype fluid-particlestructure interactions in the scale model. The factors that lead to potential scale effects in monopile scour protection experiments include: model geometry, actions of waves and currents, armour stone configuration and sediments. Unique scaling laws are applied to each factor to obtain maximum similarities between prototype and scale model, however, a full similarity is impossible to achieve due to the fact that the similarities for flow field, sediment and fluid-particle-structure dynamics cannot be satisfied at the same time [31,37-39].

Though scale effects are usually perceived as the primary cause of differences between scale and prototype model test results, it is crucial to identify that the scale effects can only be validated and analysed when the measurement effects and the model effects are clearly quantified a priori. Unlike for overtopping events, where repeated tests are quite common for quantifying the model effects $[40,41]$, repeated tests are rarely performed for scour protection stability tests due to the time consumption. De Vos et al. (2012) [16] investigated the erosion damage repeatability of monopile scour protection made up with 2.5 layers of armour stones in two environmental conditions, but only three repeated tests were conducted for each condition. This paper, with an objective of quantitatively assessing the measurement and model effects, introduces a series of repeated small scale laboratory experiments to investigate armour layer erosion damage of monopile scour protection under combined wave and current. Three main works are performed: (i) the repeatability of test conditions are discussed using statistic analysis method; (ii) the measurement effects due to applied bed profile scanner are analysed by repeated measurements; (iii) The model effects are revealed through repeated tests in the same hydraulic conditions. Statistical analysis of the experimental uncertainties associated with model effects is carried out using the three dimensional damage number $\left(S_{3 D}\right)$ and provides valuable data for estimating the experimental standard deviations of the local and global damage number in such tests.

\section{Experimental Set-Up and Focus}

\subsection{Description}

The present work adopts a small scale riprap monopile scour protection model made by multi-layer small sized armour stones and tries to elaborate the causes and impacts on the armour layer damage of measurement and model effects. Two test groups, TG1 and TG2, are applied in the study. The target conditions of the two test groups are, respectively, scaled down from the selected large scale test cases, Test 10B and Test 13B, from the PROTEUS (Protection of offshore wind turbine monopiles against scouring) project testing campaign performed in the Fast Flow Facility in HRWallingford [20,22]. Firstly, the measurement effects are quantified by performing repeated measurements of the same damage profile of the armour layer. Then, the model effects for each test group are obtained through performing a statistical analysis for the repeated tests. The geometrical scaling is used for the pile model and the Froude scaling is used for the wave and current conditions, therefore, resulting in the target conditions presented in Table 1, where $d$ is the water depth, $D_{p}$ is the pile diameter, $U_{c}$ is the current velocity (negative value indicates a current opposing following waves), $H_{s}$ is the significant wave height, $T_{p}$ is the peak wave period and $N_{\text {wave }}$ is the number of waves. The scale ratios presented in Table 1 are 
the geometrical scale ratios between model and prototype, where the pile diameter of the prototype is $D_{p}=5 \mathrm{~m}$.

Table 1. Target wave and current conditions of the present tests.

\begin{tabular}{|c|c|c|c|c|c|c|c|}
\hline \multirow{3}{*}{ Test ID } & \multirow{3}{*}{$\begin{array}{l}\text { Scale } \\
\text { Ratio }\end{array}$} & $\begin{array}{l}\text { Water } \\
\text { Depth }\end{array}$ & $\begin{array}{c}\text { Pile } \\
\text { Diameter }\end{array}$ & $\begin{array}{l}\text { Current } \\
\text { Velocity }\end{array}$ & $\begin{array}{c}\text { Significant } \\
\text { Wave Height }\end{array}$ & $\begin{array}{c}\text { Peak } \\
\text { Period }\end{array}$ & $\begin{array}{l}\text { Number } \\
\text { of Waves }\end{array}$ \\
\hline & & $d$ & $D_{p}$ & $U_{c}$ & $H_{s}$ & $T_{p}$ & $N_{\text {wave }}$ \\
\hline & & (m) & (m) & $(\mathrm{m} / \mathrm{s})$ & (m) & (s) & $(-)$ \\
\hline PROTEUS Test 10B & $1: 16.67$ & 0.9 & 0.3 & -0.330 & 0.191 & 2.00 & 3000 \\
\hline TG1 & $1: 50$ & 0.3 & 0.1 & -0.191 & 0.064 & 1.16 & 3000 \\
\hline PROTEUS Test 13B & $1: 8.33$ & 1.5 & 0.6 & -0.570 & 0.377 & 2.28 & 3000 \\
\hline TG2 & $1: 50$ & 0.25 & 0.1 & -0.233 & 0.063 & 0.93 & 3000 \\
\hline
\end{tabular}

\subsection{Facility and Test Setup}

The experiments have been carried out in the wave flume of the Civil Engineering Department, Coastal Engineering Research Group at Ghent University (abbreviated as UGent) [42]. The dimensions of the wave flume are $30 \mathrm{~m} \times 1 \mathrm{~m} \times 1.2 \mathrm{~m}$ and the maximum operational water depth $d$ is $0.8 \mathrm{~m}$. A uni-directional current system is installed in the wave flume which can create a steady current against the incoming wave. Active wave absorption is used at the wave generation system and passive wave absorption is used at the beach side of the wave flume to absorb any reflected waves from the beach. The test setup is displayed in Figure 1. A $2.5 \mathrm{~m}$ long and $5 \mathrm{~cm}$ deep sandbox is installed in the middle of the wave flume while the pile model $\left(D_{p}=0.1 \mathrm{~m}\right)$ is fixed amid the sandbox. The extended radius of the armour layer is $2.5 D_{p}(0.25 \mathrm{~m})$.

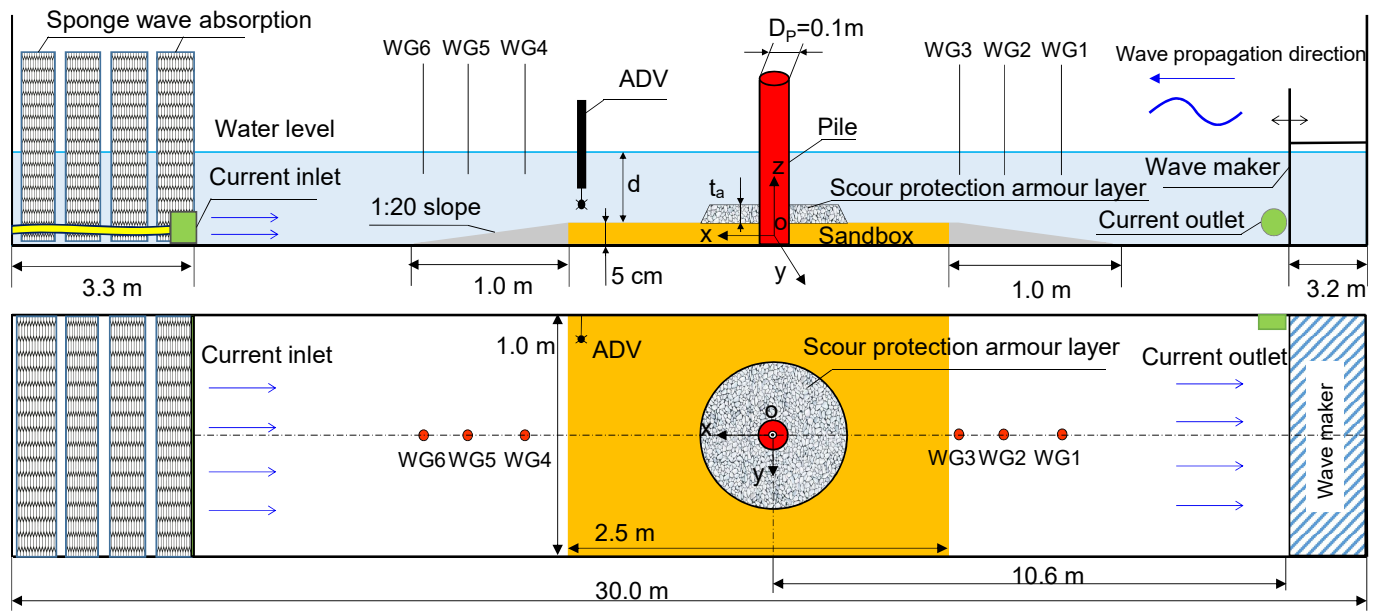

(a)

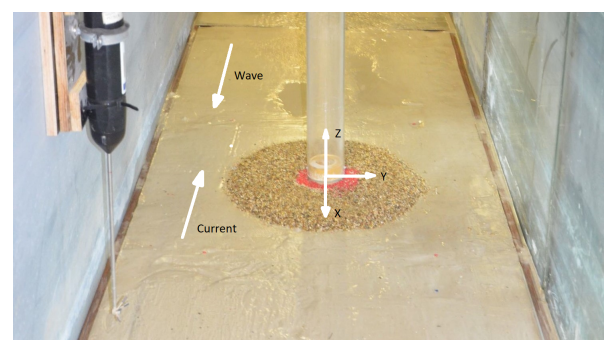

(b)

Figure 1. Scour protection model around a scale model of a single OWT monopile: (a) Sketch of the layout of wave flume experimental setup (not to scale); (b) Illustration of the model installed in the UGent wave flume. 
Six resistive wave gauges (abbreviated as WGs) are deployed in the wave flume, in which WG1-WG3 are located in the wave incoming side for collecting the wave signals and WG4-WG6 are near the passive wave absorption system for measuring wave reflection. The accuracy of this type wave gauge is $1 \mathrm{~mm}$ and the sampling frequency is $40 \mathrm{~Hz}$. A Vectrino [43] Acoustic Doppler Velocimeter (abbreviated as ADV) is employed to measure the depth-average current velocity at the vertical location of $z=0.4 d$. The sampling frequency is $25 \mathrm{~Hz}$. The locations of all probes are listed in Table 2.

Table 2. Locations of probes in small scale test.

\begin{tabular}{ccccc}
\hline \multirow{2}{*}{ Probe Location } & \multicolumn{2}{c}{ TG1 } & \multicolumn{2}{c}{ TG2 } \\
\cline { 2 - 5 } & $\mathbf{X}(\mathbf{m})$ & $\mathbf{Y}(\mathbf{m})$ & $\mathbf{X}(\mathbf{m})$ & $\mathbf{Y}(\mathbf{m})$ \\
\hline Pile centre & 0.00 & 0.00 & 0.00 & 0.00 \\
WG1 & -2.59 & 0.00 & -2.59 & 0.00 \\
WG2 & -2.18 & 0.00 & -2.18 & 0.00 \\
WG3 & -1.88 & 0.00 & -1.88 & 0.00 \\
WG4 & 9.20 & 0.00 & 9.41 & 0.00 \\
WG5 & 9.37 & 0.00 & 9.53 & 0.00 \\
WG6 & 9.70 & 0.00 & 9.70 & 0.00 \\
ADV & 0.80 & -0.45 & 0.80 & -0.45 \\
\hline
\end{tabular}

The sieve diameters and the grading curve of armour layer stones are provided in Table 3 and Figure 2. $D_{s}$ is the sieve size. $D_{16}, D_{50}$ and $D_{84}$ represent the stone diameters with $16 \%, 50 \%$ and $84 \%$ grain passing rates, respectively, where $D_{50}$ is also known as the median stone size. $D_{84} / D_{16}$ is the grading coefficient of the material. $D_{n 50}$ is the mean nominal stone diameter and $D_{n 50}=0.84 D_{50}$. The material density is $\rho_{s}=2650 \mathrm{~kg} / \mathrm{m}^{3}$ and the total mass of armour stones is $5.36 \mathrm{~kg}$. The target average armour layer thickness is $t_{a}=17 \mathrm{~mm}$, which equals to nine layers of armour stones $\left(9 D_{n 50}\right)$. The construction of the armour layer applies a single-layer configuration where no geotextile nor granular filter is used. The relatively fine armour stone size $\left(D_{50}=2.26 \mathrm{~mm}\right)$ strives for a dynamically stable scour protection at the end state under designated wave and current condition. Uniform and fine sands are used to model the bed sediment, the median size is $d_{s}=100 \mu \mathrm{m}$. Applying the Froude scaling rule for the particle fall velocity $w_{s}$ [44], the prototype sediment size can be estimated using the van Rijn formulas (Equations (1)-(3)) [45], which yields a prototype sediment size of $375 \mu \mathrm{m}$.

Table 3. Size and grading coefficient of applied armour stones.



In Equations (1)-(3), $v$ is the kinematic viscosity coefficient of water, $s$ is the ratio between sediment density and water density. $g$ is the acceleration due to gravity. 


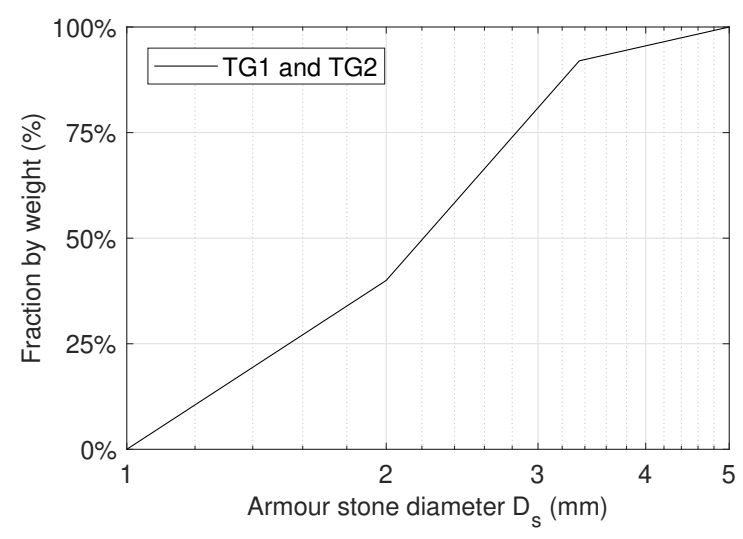

Figure 2. Armour stones applied in the present experiment.

The intact and damaged profiles of the scour protection armour layer before and after wave and current action are measured by means of the Faro ${ }^{\circledR}$ Freestyle 3D handheld laser scanner [46] (Figure 3a). The raw scanned data is post-processed into an orthogonally gridded format by means of an averaging filter (Figure 3b). The grid resolution is $2 \mathrm{~mm}$, which is close to the size of the armour stone and can well depict the deformation of the armour layer. A validation case is done in dry conditions by measuring a cuboid of $90 \mathrm{~mm} \times 45 \mathrm{~mm} \times 45 \mathrm{~mm}$. The theoretical volume of the cuboid is $182,250 \mathrm{~mm}^{3}$ and the measured volume is $182,125 \mathrm{~mm}^{3}$, the relative error is $0.06 \%$ [36]. However, due to the system randomness in calibration and data collection, the measurement effect is unavoidable and will be analysed in this work through repeated measurements.

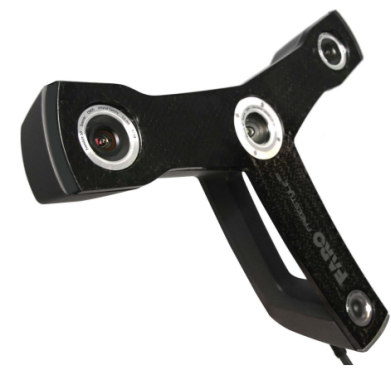

(a)

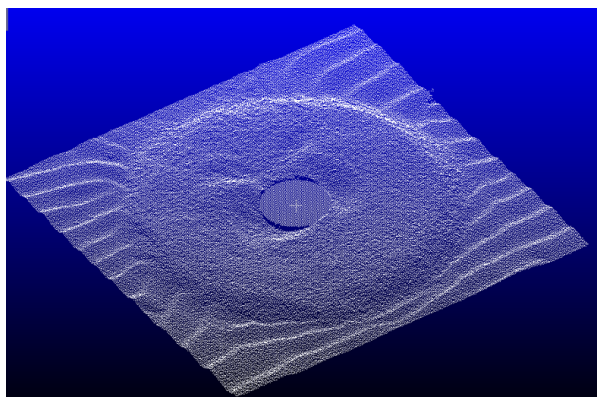

(b)

Figure 3. Faro ${ }^{\circledR}$ Freestyle 3D handheld laser scanner and post-processing: (a) Handheld laser scanner; (b) Post-processed gridded profile data obtained using the handheld laser scanner.

\subsection{Test Matrix}

The measured conditions for each repeated test in the two test groups are listed in Table 4 , including water depth $d$, depth-averaged current velocity $U_{c}$, significant wave height $H_{s}, 1 / 10$ wave height $H_{1 / 10}$, maximum wave height $H_{\text {max }}$, peak period $T_{p}$ and mean energy periods $T_{m-1,0}$. For each test group, seven repeated tests are performed. Irregular waves using Jonswap spectra and peak enhancement factor $\gamma=3.3$ are applied in each test, with the wave duration set to $3000 T_{p}$. The same wave trains are applied for TG1_1 to TG1_3 and TG2_1 to TG2_3 with the purpose to investigate the differences of armour layer damage between using the same and distinct wave trains. 
Table 4. Test matrix.

\begin{tabular}{cccccccc}
\hline & $\begin{array}{c}\text { Water } \\
\text { Depth }\end{array}$ & $\begin{array}{c}\text { Current } \\
\text { Velocity }\end{array}$ & $\begin{array}{c}\text { Significant } \\
\text { Wave Height }\end{array}$ & $\begin{array}{c}\mathbf{1} / \mathbf{1 0} \text { Wave } \\
\text { Height }\end{array}$ & $\begin{array}{c}\text { Maximum } \\
\text { Wave Height }\end{array}$ & $\begin{array}{c}\text { Peak } \\
\text { Period }\end{array}$ & $\begin{array}{c}\text { Mean Energy } \\
\text { Period }\end{array}$ \\
\cline { 2 - 8 } & $\boldsymbol{d}$ & $\boldsymbol{U}_{\boldsymbol{c}}$ & $\boldsymbol{H}_{\boldsymbol{s}}$ & $\boldsymbol{H}_{\mathbf{1 / 1 0}}$ & $\boldsymbol{H}_{\boldsymbol{m a x}}$ & $\boldsymbol{T}_{\boldsymbol{p}}$ & $\boldsymbol{T}_{\boldsymbol{m}-\mathbf{1 , 0}}$ \\
\hline Test_1 & $\mathbf{( m )}$ & $\mathbf{( m / s )}$ & $\mathbf{( m )}$ & $\mathbf{( m )}$ & $\mathbf{( m )}$ & $\mathbf{( s )}$ & $\mathbf{( s )}$ \\
\hline TG1_2 & 0.3 & -0.187 & 0.063 & 0.080 & 0.214 & 1.182 & 1.074 \\
TG1_3 & 0.3 & -0.190 & 0.064 & 0.081 & 0.279 & 1.147 & 1.072 \\
TG1_4 & 0.3 & -0.183 & 0.063 & 0.079 & 0.236 & 1.164 & 1.072 \\
TG1_5 & 0.3 & -0.183 & 0.064 & 0.080 & 0.224 & 1.164 & 1.065 \\
TG1_6 & 0.3 & -0.186 & 0.063 & 0.080 & 0.273 & 1.164 & 1.073 \\
TG1_7 & 0.3 & -0.187 & 0.062 & 0.079 & 0.224 & 1.138 & 1.071 \\
\hline TG2_1 & 0.25 & -0.222 & 0.063 & 0.079 & 0.211 & 1.138 & 1.072 \\
TG2_2 & 0.25 & -0.221 & 0.062 & 0.078 & 0.195 & 0.978 & 0.922 \\
TG2_3 & 0.25 & -0.221 & 0.063 & 0.077 & 0.204 & 0.954 & 0.923 \\
TG2_4 & 0.25 & -0.219 & 0.062 & 0.078 & 0.228 & 0.954 & 0.920 \\
TG2_5 & 0.25 & -0.217 & 0.063 & 0.078 & 0.174 & 0.973 & 0.923 \\
TG2_6 & 0.25 & -0.221 & 0.061 & 0.076 & 0.193 & 0.985 & 0.923 \\
TG2_7 & 0.25 & -0.217 & 0.062 & 0.078 & 0.177 & 0.985 & 0.927 \\
\hline
\end{tabular}

\subsection{Repeatability of Wave and Current Conditions, Generated in the Laboratory}

Repeatability of the employed hydrodynamic conditions is crucial for evaluating the model effects. The inherent system randomness in wave and current generation causes the instantaneous flow to vary between each repeated test, no matter whether the wave and/or current generation inputs are manually or automatically controlled. The repeatability can be evaluated by considering the same location, the same experimental tools, the same observer, the same measuring instruments, the same conditions and the same objectives, and can be quantified with the dispersion characteristics of the results, such as the standard deviation of the measurement result, $\sigma(q)$, calculated with Equation (4), and, the standard deviation of the mean value, $\sigma(\bar{q})$, calculated with Equation (5) [47],

$$
\begin{gathered}
\sigma(q)=\sqrt{\sigma^{2}(q)}=\sqrt{\frac{1}{n-1} \sum_{i=1}^{n}(q-\bar{q})^{2}} \\
\sigma(\bar{q})=\sqrt{\frac{1}{n} \sigma^{2}(q)}=\sqrt{\frac{1}{n}} \sigma(q)
\end{gathered}
$$

where $q$ is the measured quantity, $\bar{q}$ is the arithmetic mean value of $q$, as defined in Equation (6),

$$
\bar{q}=\frac{1}{n} \sum_{i=1}^{n} q_{i}
$$

$n$ is the number of measurements and $\sigma^{2}(q)$ is the variance of measurements. $\sigma(q)$ reflects the degree of data dispersion and the $\sigma(\bar{q})$ expresses the precision of the mean value. Ideal repeatability requires $\sigma(q)$ and $\sigma(\bar{q})$ to be as small as possible. According to [47], Equations (4) and (5) are also used for quantifying the Type A uncertainty in repeated measurements and experiments, where the Type A uncertainty refers to an uncertainty result which is obtained by direct statistical analysis of series repeated observations.

For the tests with the same wave trains, the measured wave surface elevations of TG_1 to TG_3 are plotted in Figure 4, where the wave peaks and troughs and up/down crossings are well repeated through visual assessment. However, differences can still be noticed as a result of the randomness due to the flow turbulence and the interaction with currents. The wave statistical characteristics are apparently not sensitive to the wave train repeatability, as seen in the plotted measured wave spectra (Figure 5) and wave height 
exceeding probability distributions (Figure 6). Figure 7 shows the current flow turbulent energy spectra, respectively. Prior to analysing the turbulence, the measured velocity signals were despiked and detrended. The turbulence of the current in longitudinal flow direction is analysed using the spectral method of Richard et al. (2013) [48] taking into account the noise of the ADV. According to [48] the turbulence intensity, $T_{i}$, is defined as Equation (7),

$$
T_{i}=\frac{\sqrt{u^{\prime 2}-\sigma_{n}^{2}}}{u} \times 100(\%)
$$

where $u^{\prime 2}$ is the square sum of the velocity perturbation, $u$ is the mean velocity and $\sigma_{n}^{2}$ is the variance due to noise of the ADV. The variance due to noise is derived from a two parameter best-fit line (dotted black line in Figure 7) as proposed by [48]. When the bestfit line plateaus towards the right end of Figure 7 the turbulence noise floor is reached. Towards the left of Figure 7 the best-fit line aligns well with the $f_{t}^{-5 / 3}$ line indicating the inertial subrange. It can be seen that the measurements from repeated tests cover the same range in the spectral plot (Figure 7).

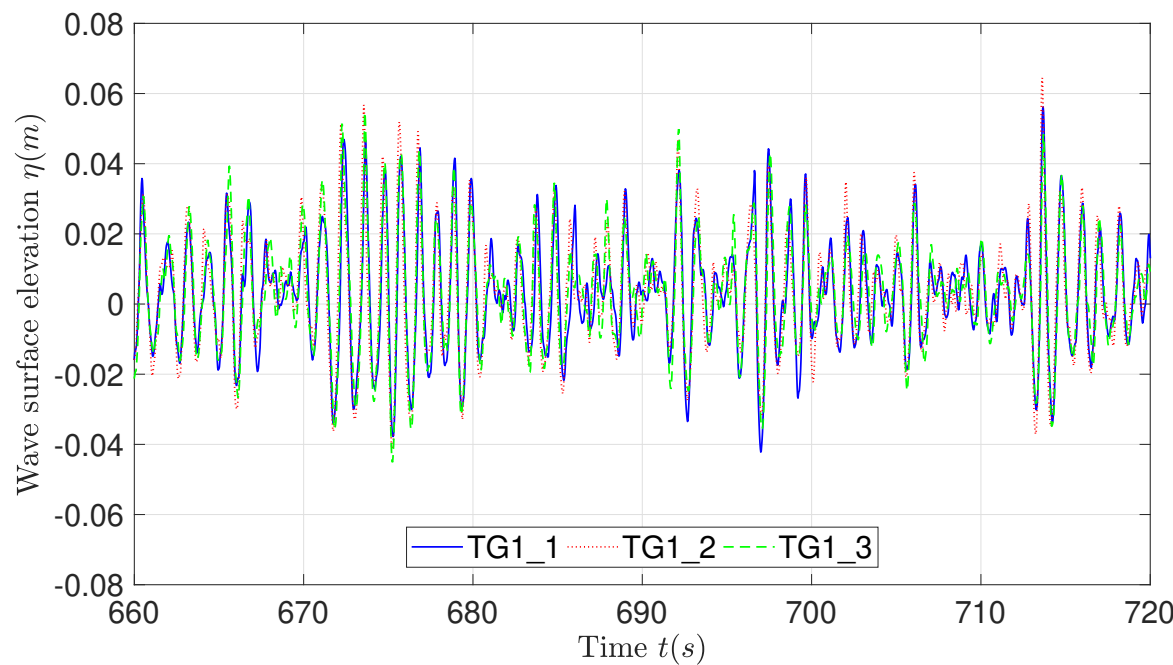

Figure 4. Repeatability of measured wave surface elevation (TG1_1 to TG1_3).

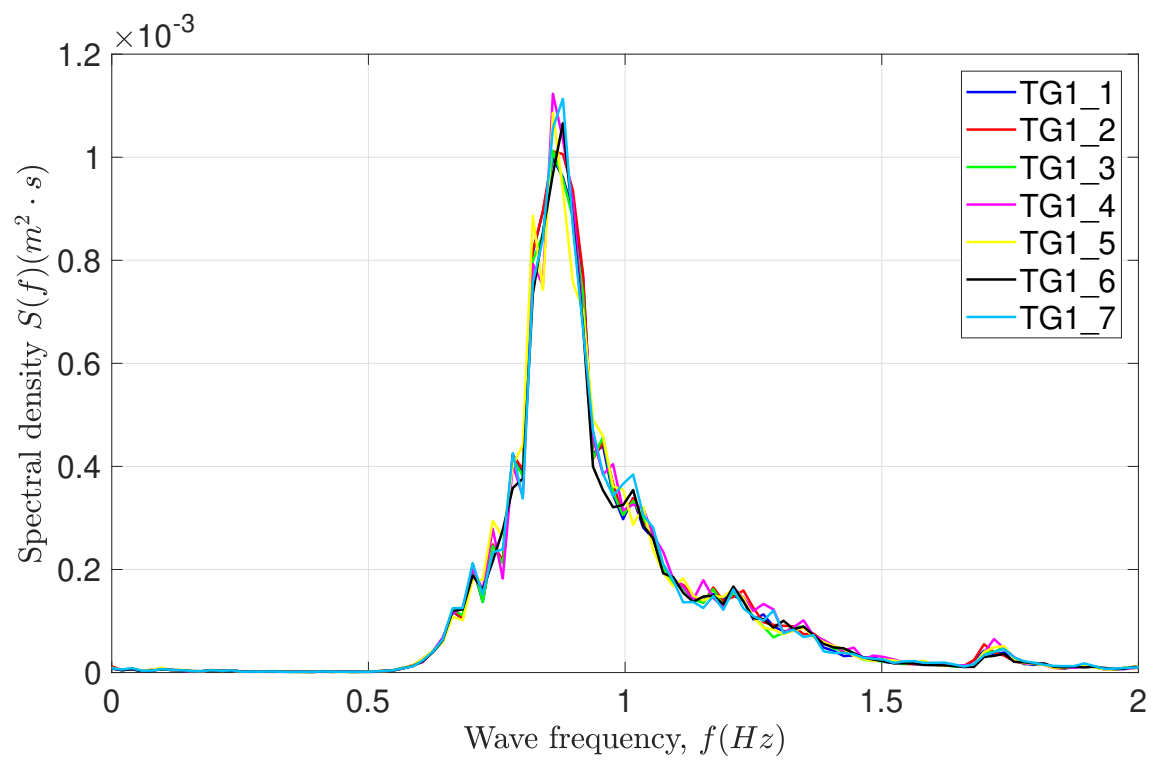

Figure 5. Measured wave spectra (TG1). 


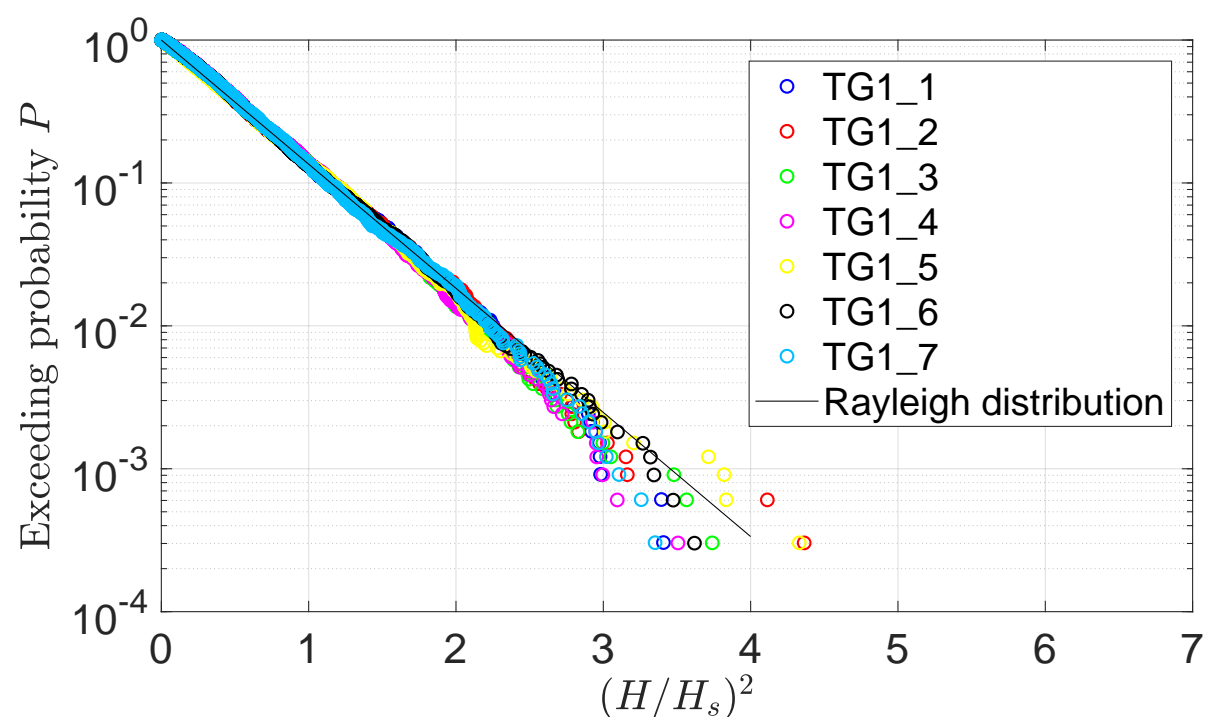

Figure 6. Wave height distributions (TG1).

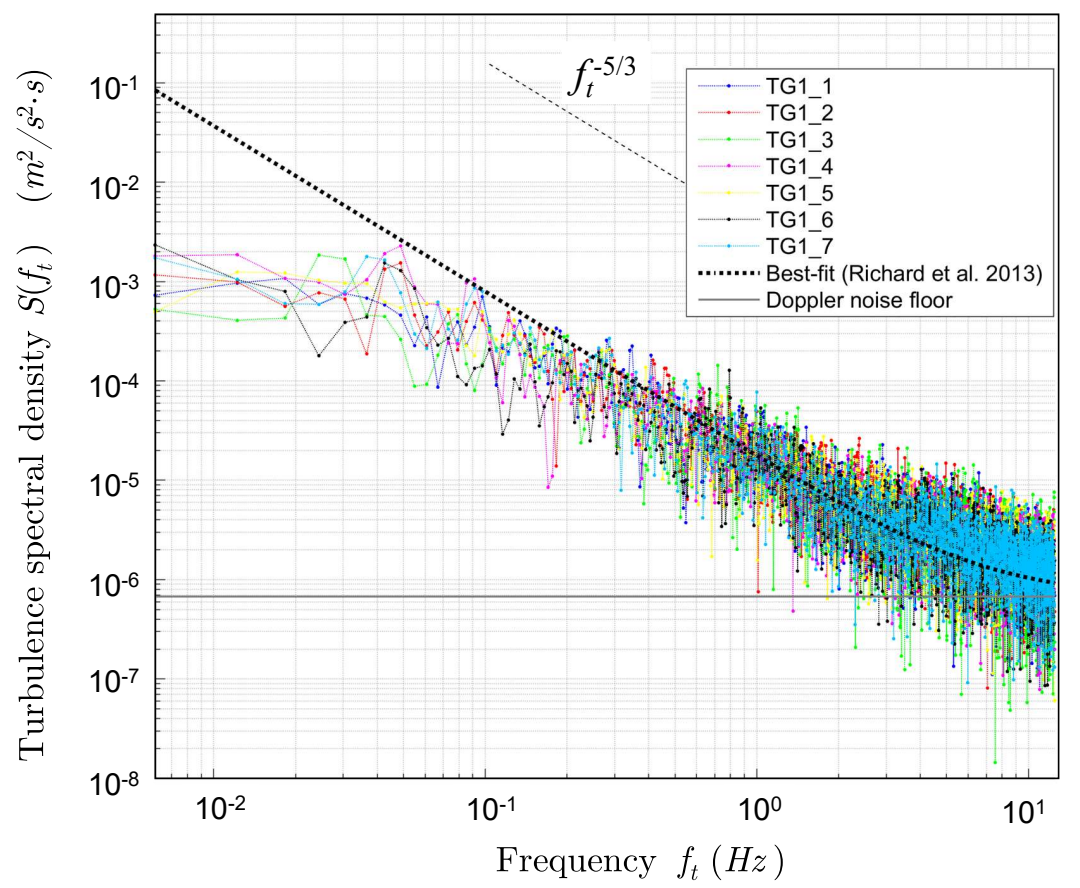

Figure 7. Measured current turbulent energy spectra (TG1).

Table 5 lists the repeatability analysis results for the measured wave and current conditions. The standard deviations and standard deviations of the mean of the parameters are both ideally small for the repeated tests, except for $H_{\max } . H_{\max }$ records the maximum wave height in 3000 waves, which corresponds to an exceeding probability of approximately $0.03 \%$ in the present tests. Compared with $H_{s}$ and $H_{1 / 10}, H_{\text {max }}$ has a higher standard deviation, as it is affected by the instantaneous superposition of the incoming waves, reflected waves from the absorption structure, diffracted waves from the pile and the interactions between waves and currents. Further, the measured turbulent intensities of repeated tests show a standard deviation below $0.53 \%$. This leads to the conclusion that uncertainties in turbulence intensity for repeated tests are limited. 
Table 5. Repeatability of measured wave and current parameters.

\begin{tabular}{cccccccc}
\hline TG1 & $\boldsymbol{H}_{\boldsymbol{s}}(\mathbf{m})$ & $\boldsymbol{H}_{\mathbf{1 / 1 0}}(\mathbf{m})$ & $\boldsymbol{H}_{\max }(\mathbf{m})$ & $\boldsymbol{T}_{\boldsymbol{p}}(\mathbf{s})$ & $\boldsymbol{T}_{\boldsymbol{m - 1 , 0}}(\mathbf{s})$ & $\boldsymbol{U}_{\boldsymbol{c}}(\mathbf{m} / \mathbf{s})$ & $\boldsymbol{T}_{\boldsymbol{i}} \mathbf{( \% )}$ \\
\hline $\bar{q}$ & 0.063 & 0.080 & 0.237 & 1.16 & 1.07 & -0.186 & 6.57 \\
$\sigma(q)$ & 0.0007 & 0.0008 & 0.0275 & 0.016 & 0.003 & 0.0025 & 0.32 \\
$\sigma(\bar{q})$ & 0.0003 & 0.0003 & 0.0104 & 0.006 & 0.001 & 0.0009 & 0.12 \\
\hline TG2 & $\boldsymbol{H}_{\boldsymbol{s}} \mathbf{( m )}$ & $\boldsymbol{H}_{\mathbf{1 / 1 0}}(\mathbf{m})$ & $\boldsymbol{H}_{\max }(\mathbf{m})$ & $\boldsymbol{T}_{\boldsymbol{p}}(\mathbf{s})$ & $\boldsymbol{T}_{\boldsymbol{m}-\mathbf{1 , 0}}(\mathbf{s})$ & $\boldsymbol{U}_{\boldsymbol{c}}(\mathbf{m} / \mathbf{s})$ & $\boldsymbol{T}_{\boldsymbol{i}} \mathbf{( \% )}$ \\
\hline $\bar{q}$ & 0.062 & 0.078 & 0.195 & 0.97 & 0.92 & -0.220 & 6.57 \\
$\sigma(q)$ & 0.0008 & 0.0007 & 0.0180 & 0.013 & 0.002 & 0.0021 & 0.53 \\
$\sigma(\bar{q})$ & 0.0003 & 0.0003 & 0.0068 & 0.005 & 0.001 & 0.0008 & 0.20 \\
\hline
\end{tabular}

\subsection{Repeatability of Armour Layer Flatness}

The manual placement of armour stones makes it difficult to build a perfectly flat armour layer. The armour stones are randomly distributed and form a rough and rugged surface, as sketched in Figure 8. The averaged armour layer thickness and the flatness of the initial profile compose an important source of uncertainty in model building. Given the bed surface elevation in each grid point in the armour layer area (noted as $Z$ ), the flatness $F$ can be expressed by a ratio between the standard deviation of bed surface elevation $\sigma(Z)$ and the averaged layer thickness $t_{a}$, as Equation (8),

$$
F=\frac{\sigma(Z)}{t_{a}}
$$

where, $\sigma(Z)$ is given in Equation (9),

$$
\sigma(Z)=\sqrt{\frac{1}{M-1} \sum_{k=1}^{M}(Z-\bar{Z})^{2}}
$$

and,

$$
\bar{Z}=\frac{1}{M} \sum_{k=1}^{M} Z
$$

$M$ is the number of grid points, $F=0$ represents a flat surface. The edge of the scour protection (region with radius from $0.2 \mathrm{~m}$ to $0.28 \mathrm{~m}$ ) contains reposed armour stones and will result in a high standard deviation of layer thickness, thus is neglected in computing $\sigma(Z)$ and $F$. The results of layer thickness and flatness are shown in Table 6. The $F$ value for each test is approximately 0.1 , representing the surface coarseness is $10 \%$ of the thickness. The standard deviation of bed surface elevation $\sigma(Z)$ is around $2 \mathrm{~mm}$, which reasonably matches the stone size. The standard deviations of the layer thickness $\sigma\left(t_{a}\right)$ and of the flatness $\sigma(F)$ can be calculated through Equation (4). The standard deviations of the mean values, $\sigma\left(\overline{t_{a}}\right)$ and $\sigma(\bar{F})$, are calculated through Equation (5). Statistically, for each test group, $\sigma\left(t_{a}\right) \approx 0.6 \mathrm{~mm}$ and $\sigma(F) \approx 0.011$ to 0.021 , as listed in Table 7 . The results indicate a reasonable repeatability of the armour layer construction with regard to the thickness, but repeatability for the flatness is not ideal. Meanwhile, there remain several factors that are not strictly treated within the present work, such as the edge repose angles and the exact armour stone volume of each subarea. Overall, the manual construction of armour layer is one important source of randomness and uncertainty herein the experimental conditions. 


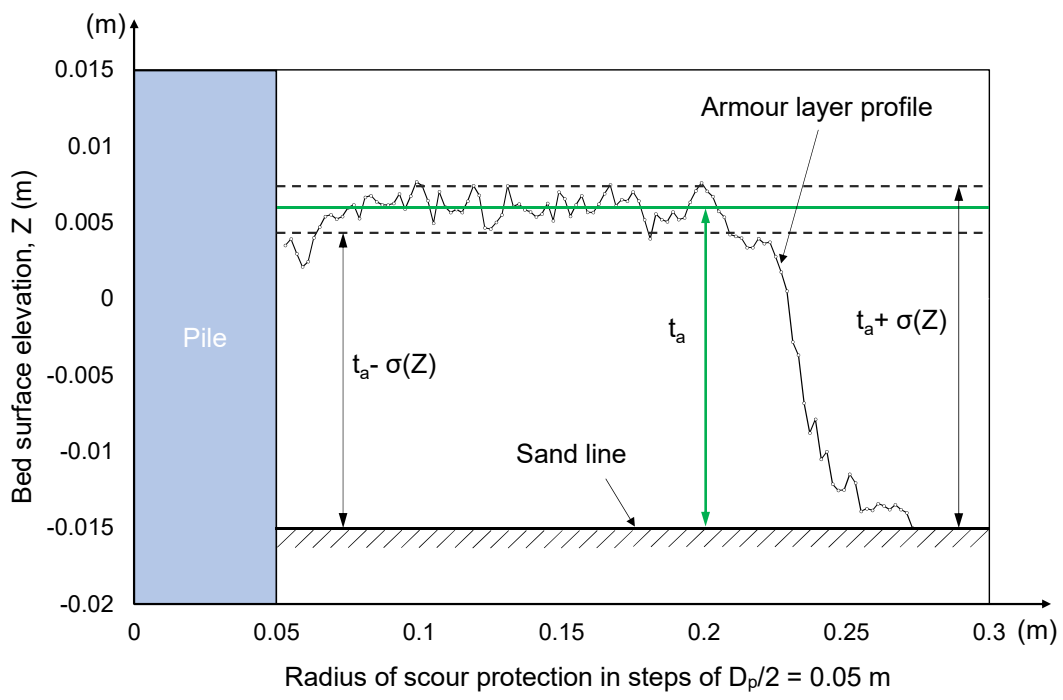

Figure 8. Sketch of flatness of armour layer thickness.

Table 6. Layer thickness, $t_{a}$ and flatness, $F$, from initial scans of the armour layer.

\begin{tabular}{cccccccc}
\hline Test ID & $\begin{array}{c}\boldsymbol{t}_{\boldsymbol{a}} \\
(\mathbf{m m})\end{array}$ & $\begin{array}{c}\sigma(\mathbf{Z}) \\
(\mathbf{m m})\end{array}$ & $\begin{array}{c}\boldsymbol{F} \\
\mathbf{( - )}\end{array}$ & Test ID & $\begin{array}{c}\boldsymbol{t}_{\boldsymbol{a}} \\
(\mathbf{m m})\end{array}$ & $\begin{array}{c}\sigma(Z) \\
(\mathbf{m m})\end{array}$ & $\begin{array}{c}\boldsymbol{F} \\
(-)\end{array}$ \\
\hline TG1_1 & 16.5 & 1.7 & 0.11 & TG2_1 & 18.5 & 1.8 & 0.10 \\
TG1_2 & 18.4 & 1.6 & 0.08 & TG2_2 & 18.5 & 1.7 & 0.09 \\
TG1_3 & 17.6 & 1.4 & 0.08 & TG2_3 & 18.1 & 2.0 & 0.11 \\
TG1_4 & 17.6 & 2.5 & 0.14 & TG2_4 & 18.4 & 1.6 & 0.08 \\
TG1_5 & 17.5 & 1.9 & 0.11 & TG2_5 & 17.1 & 1.8 & 0.11 \\
TG1_6 & 18.1 & 1.5 & 0.09 & TG2_6 & 17.8 & 1.9 & 0.11 \\
TG1_7 & 18.1 & 2.1 & 0.11 & TG2_7 & 17.2 & 1.5 & 0.09 \\
\hline
\end{tabular}

Table 7. Repeatability of flatness of initial scans.

\begin{tabular}{ccccccc}
\hline Test Group & $\begin{array}{c}\overline{\boldsymbol{t}_{\boldsymbol{a}}} \\
(\mathbf{m m})\end{array}$ & $\begin{array}{c}\overline{\boldsymbol{F}} \\
\mathbf{( - )}\end{array}$ & $\begin{array}{c}\sigma\left(\boldsymbol{t}_{\boldsymbol{a}}\right) \\
(\mathbf{m m})\end{array}$ & $\begin{array}{c}\sigma(\boldsymbol{F}) \\
(-)\end{array}$ & $\begin{array}{c}\sigma\left(\overline{\boldsymbol{t}_{a}}\right) \\
(\mathbf{m m})\end{array}$ & $\begin{array}{c}\sigma(\overline{\boldsymbol{F}}) \\
(-)\end{array}$ \\
\hline TG_1 & 17.7 & 0.103 & 0.62 & 0.021 & 0.24 & 0.008 \\
TG_2 & 17.9 & 0.099 & 0.60 & 0.011 & 0.23 & 0.004 \\
\hline
\end{tabular}

\section{Results}

\subsection{Damage Number}

The damage of scour protection armour layer is quantified based on the methodology proposed by De Vos et al. (2012) [16]. The armour layer is divided into four rings and 24 subareas (Figure 9). Each subarea has the same area as the pile sectional area, $S_{P}$, $S_{P}=\pi D_{p}^{2} / 4$. The damage number $\left(S_{3 D, i}\right)$ in each subarea is given in Equation (11) and the global damage number $\left(S_{3 D}\right)$ is defined as the maximum of $S_{3 D, i}$ in Equation (12),

$$
\begin{aligned}
& S_{3 D, i}=\frac{V_{i}}{D_{n 50} \cdot S_{P}} \\
& S_{3 D}=\max \left(S_{3 D, i}\right)
\end{aligned}
$$

where $i$ is the index of the subarea and $V_{i}$ is the eroded volume in each subarea after wave and current action. $S_{3 D, i}=1$ represents a volume equivalent to one layer of armour stones in subarea $i$ is eroded. This damage number can well depict the dynamic stability of the scour protection. According to [16], for an armour layer made up with 2.5 layer of armour stones, a dynamic failure is observed when $S_{3 D}>1$. Compared with the STAB parameter 
introduced in Den Boon et al. (2004) [14], the advantage of using the $S_{3 D}$ and $S_{3 D, i}$ numbers is that it becomes easier to identify the location of the erosion and therefore assess the level of the damage.

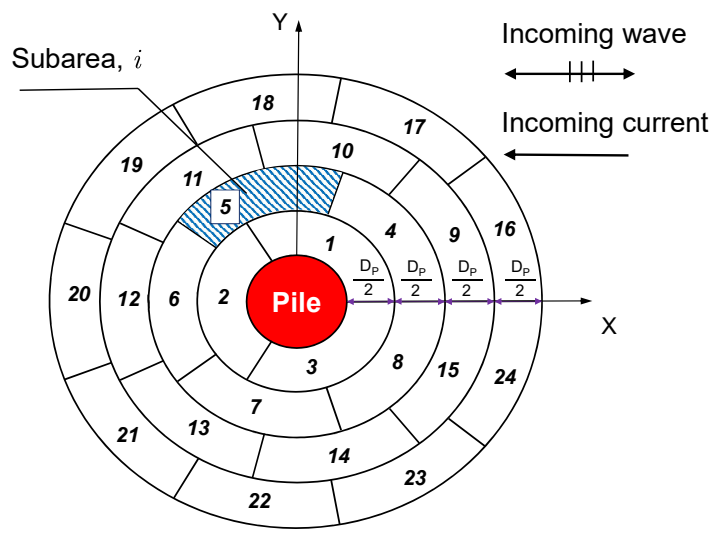

Figure 9. Subarea division of monopile scour protection armour layers.

\subsection{Measurement Effects Due to Handheld Laser Scanner}

The measurement quality of a handheld laser scanner will significantly affect the $S_{3 D}$ result mainly attributed to the disturbances from calibration, scanning speed and angle, scanning dark area, and, scanning area immersed in water. Firstly, the Cartesian system needs to be calibrated during each measurement, which can introduce small relative translation and rotation between the initial and the end profiles. Secondly, the scanning angle and speed can affect the data collection. As the handheld laser scanner captures and processes reflected infrared light to generated points in space, the scanning area needs to be slowly swept in different angles in order to avoid shadow effect. Thirdly, the quality of the measurement can deteriorate when scanning dark stones and dark areas, which is attributed to the surface absorption of light. As the armour stones are sometimes blocked by each other, the scanned profile misses points unavoidably in dark gaps between the stones despite the specific colouring of stones. This can be handled in post processing by adopting a grid resolution close to the stone diameter to maintain the best scan quality. Additionally, the scanned area should not be immersed in water as errors could be introduced due to the light refraction in water. In general, it is necessary to manipulate the handheld laser scanner and process the data carefully to minimize the inaccuracy in calibration and measurement.

The quantification of the measurement effects relies on repeated scans of the same profile in TG1_4. The end profile of this case has been scanned five times (measurements $1-5$ in Figure 10) and the damage numbers $S_{3 D, i}$ are processed using Equation (11) and are plotted in Figure 10.

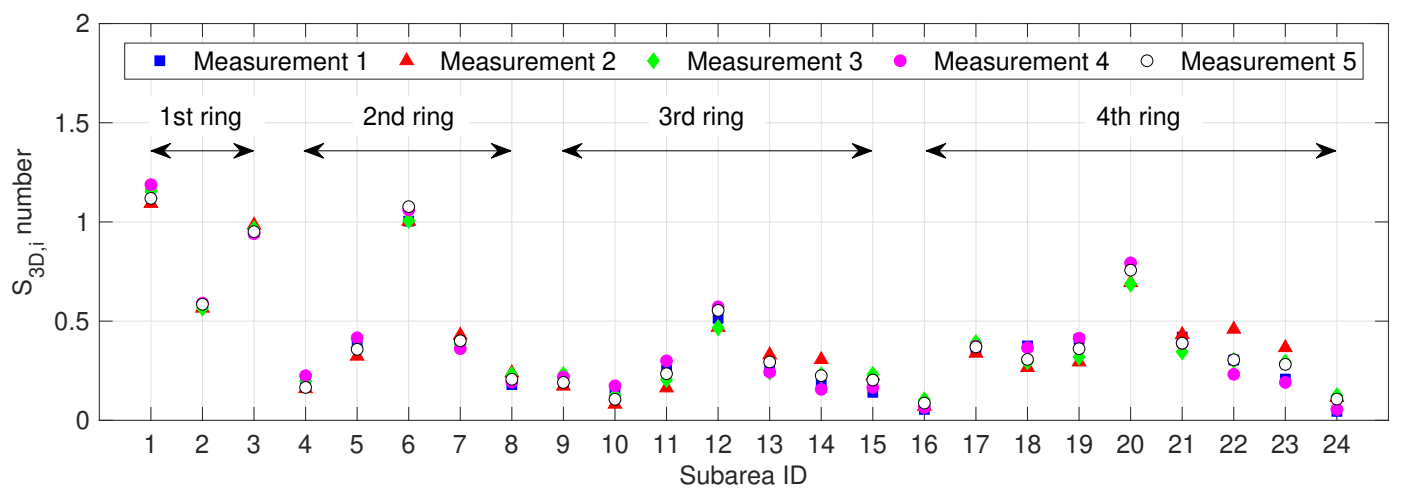

Figure 10. Results of repeated damage measurements for the case TG1_4. 
By means of a statistic analysis, the standard deviation of global damage number is $\sigma\left(S_{3 D}\right)=0.039$, the maximum difference of $S_{3 D}$ between the five measurements is 0.095. Taking into account that the layer thickness contains approximately nine layers of armour stones, the $S_{3 D}$ difference between measurements is much less than the layer number of armour stones $(0.095 / 9=1 \%)$. The maximum standard deviation of the subarea damage number is $\sigma\left(S_{3 D, i}\right)=0.083$, which occurs in subarea 22 in the 4 th ring. The higher inaccuracy of measurement in the 4th ring is attributed to the reason that the scanning vision was not complete enough to cover the reposed armour layer stones at the edge of the armour layer where the shadow effect was relatively strong. The results show a limited uncertainty due to measurement effects in the present experiment based on case TG1_4.

\subsection{Damage Patterns}

The initial and damaged profiles of the scour protection armour layers for cases TG1_1 to TG1_7 are visualized in Figure 11. Through a visual evaluation, the damage profiles exhibit similar patterns between each case. The erosion is observed mainly at two regions: (1) the two sides near the pile towards the current incoming direction $\left(45^{\circ}\right.$ to $90^{\circ}$ and $270^{\circ}$ to $\left.315^{\circ}\right)$; (2) the lee-side $\left(135^{\circ}\right.$ to $\left.225^{\circ}\right)$ and away from the pile, and forms a butterfly-like shape as observed in all end profiles presented in Figure 11. The accretion of armour stones occurs mostly in the current downstream direction $\left(90^{\circ}\right.$ to $135^{\circ}$ and $225^{\circ}$ to $\left.270^{\circ}\right)$, which is formed due to the transport process of the armour stones from the eroded regions. The damage and accretion are not symmetrical in the two sides. Meanwhile, rare erosion occurs in the incoming current upstream side $\left(315^{\circ}\right.$ to $360^{\circ}$ and $0^{\circ}$ to $45^{\circ}$, where $360^{\circ}$ coincides with $0^{\circ}$ in Figure 11). The erosion pattern matches the shear stress distribution around a cylinder pile in steady current provided in [7]. Accordingly, the damage profiles for TG2_1 to TG2_7 are visualized in Figure 12. Similar to the patterns in TG1, TG2 shows that more damage occurs in the areas near the pile towards the incoming current direction $\left(45^{\circ}\right.$ to $90^{\circ}$ and $270^{\circ}$ to $315^{\circ}$ ). The lee-side between $135^{\circ}$ and $225^{\circ}$ also suffers erosion damage, however, different from the patterns observed in TG1, the damaged areas in TG2 stretch longer in the wake and lead to significant erosions in the edge ring. Meanwhile, the accretions of armour stones in areas from $90^{\circ}$ to $135^{\circ}$ and from $225^{\circ}$ to $270^{\circ}$ are not obvious. This is attributed to the fact that the stones that are initiated from the side of the pile by the high flow velocity around the pile are moved to the lee-side area, where strong lee-wake vortex brings them further out of the edge. The photos of the end states of TG1_4 and TG2_4 presented in Figure 13 directly reflect the damage areas. Through visual assessment, the scour protections are dynamically stable in these tests, as there is no exposure of sediment beneath the armour layer.

Under the applied hydraulic conditions in TG1, the armour layer remains intact in the pure current action scenario. It is asserted that the presence of wave induced bottom velocity triggers the erosion. Regarding the conditions of waves opposing current, it is observed that the armour stones near the pile start to roll upward when a low wave trough passes the pile and stop rolling or fall down when a following wave crest passes. The high wave crest can also entrain some armour stones back towards the current incoming direction. The motion modes of the transported armour stones are mainly rolling and flipping, while a small amount of fine grains are floating and suspended for a very short time, usually within one second. However, with the high current boundary condition used in TG2, some armour stones are already moved by the pure action of the current within the current acceleration stage ( $5 \mathrm{~min}$ for every test), leading to higher erosions in the wake region and at the edge of the armour layer. For both TG1 and TG2, the current alone action does not initiate the sediment motion away from the influenced pile zone, which yields clear-water conditions. When waves are superposed, the sediments are suspended due to the oscillatory flow and then transported by the current out of the boundary layer. Small sand ripples are observed everywhere out of the scour protection region in the sandbox. Therefore, these tests are conducted in live-bed conditions. Nevertheless, the bed 
deformation is relatively small to the pile diameter and the erosion failure due to large bed deformation is not observed in the present experiments.

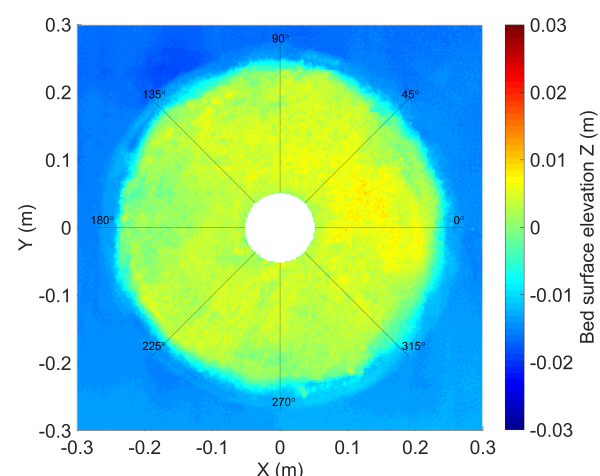

(a)

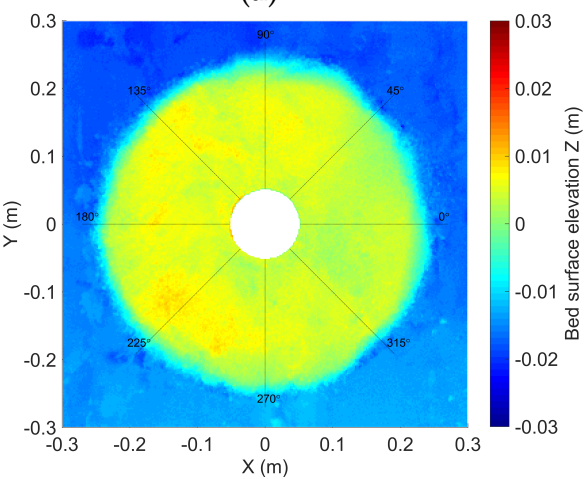

(c)

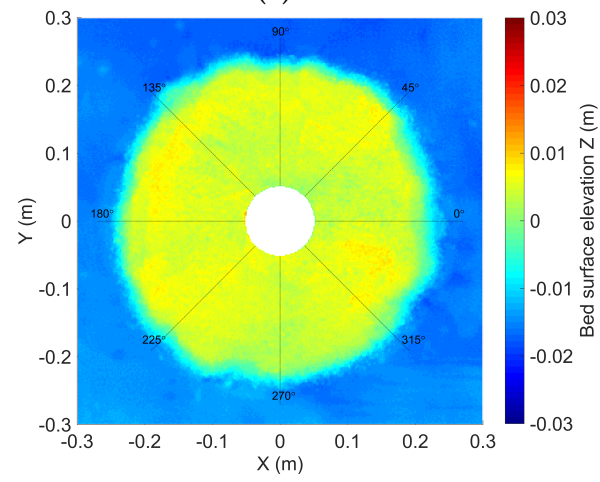

(e)

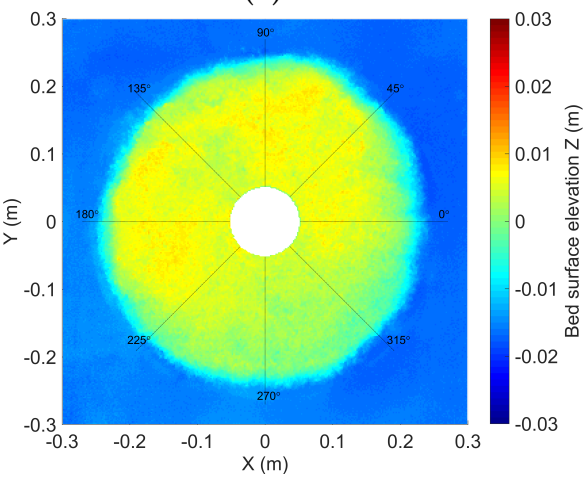

$(\mathrm{g})$

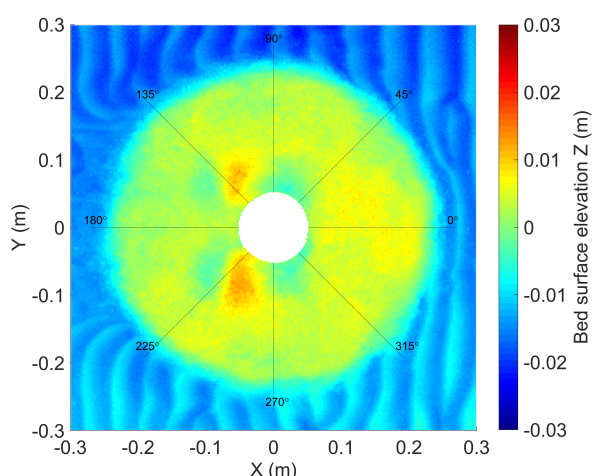

(b)

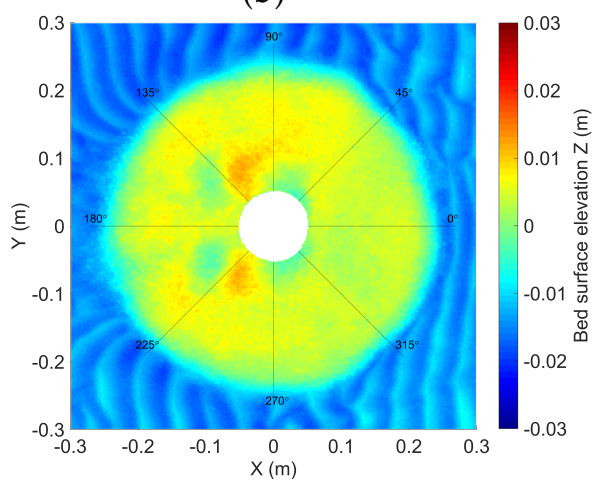

(d)

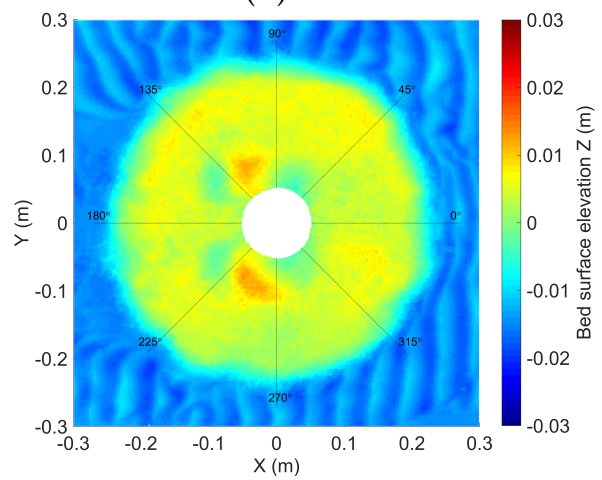

$(\mathbf{f})$

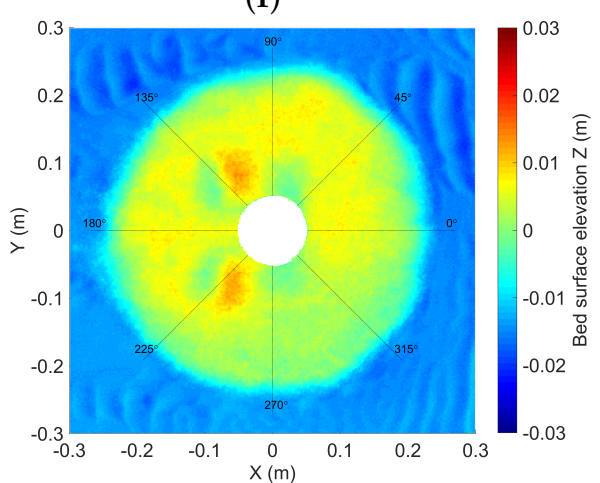

(h)

Figure 11. Cont. 


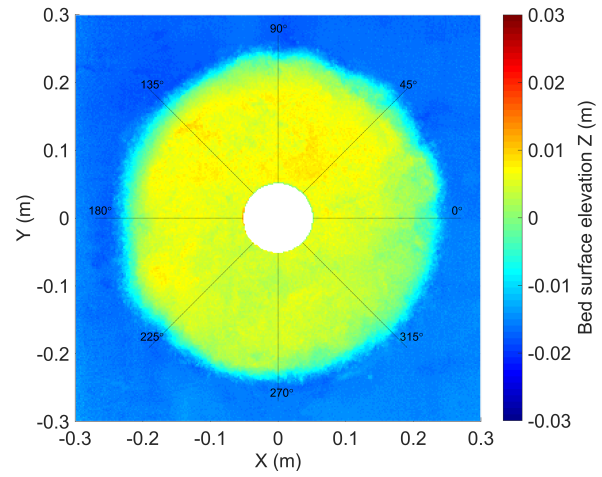

(i)

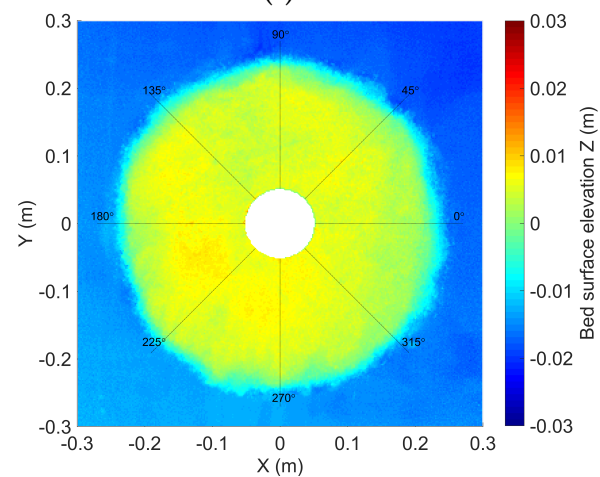

(k)

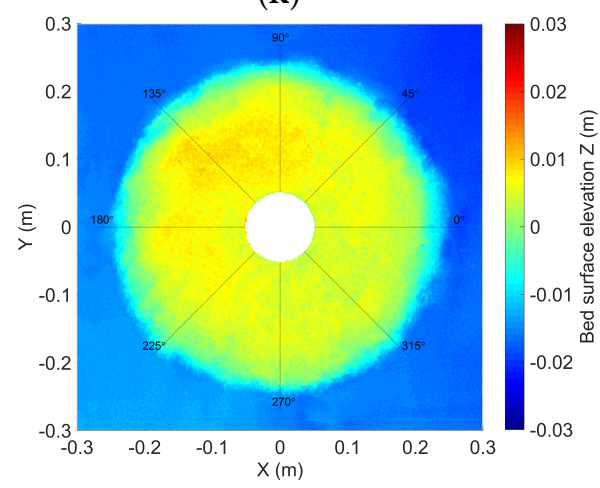

(m)

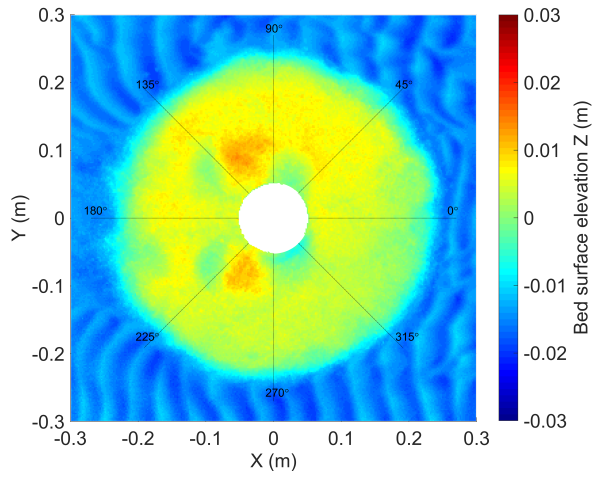

(j)

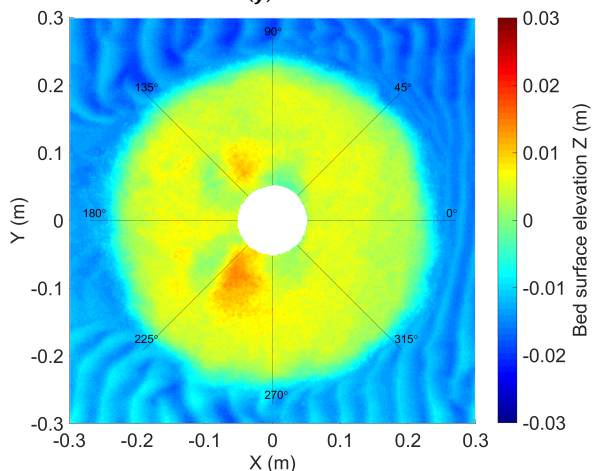

(1)

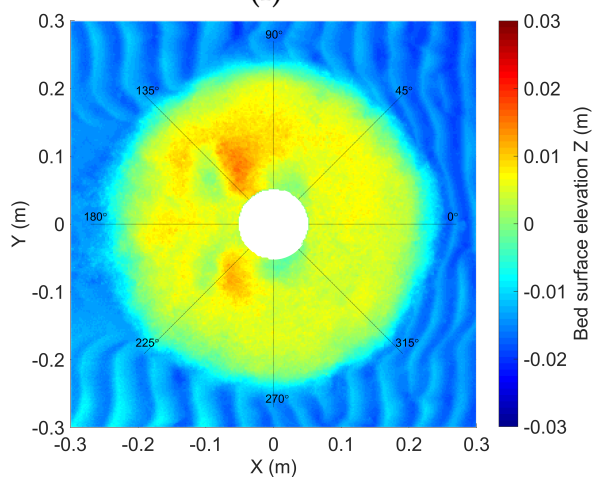

(n)

Figure 11. Initial and end profiles of TG1: (a) TG1_1 initial profile; (b) TG1_1 end profile; (c) TG1_2 initial profile; (d) TG1_2 end profile; (e) TG1_3 initial profile; (f) TG1_3 end profile; (g) TG1_4 initial profile; (h) TG1_4 end profile; (i) TG1_5 initial profile; (j) TG1_5 end profile; (k) TG1_6 initial profile; (1) TG1_6 end profile; (m) TG1_7 initial profile; (n) TG1_7 end profile. The Cartesian system presented in Figure 9 is employed. 




(a)

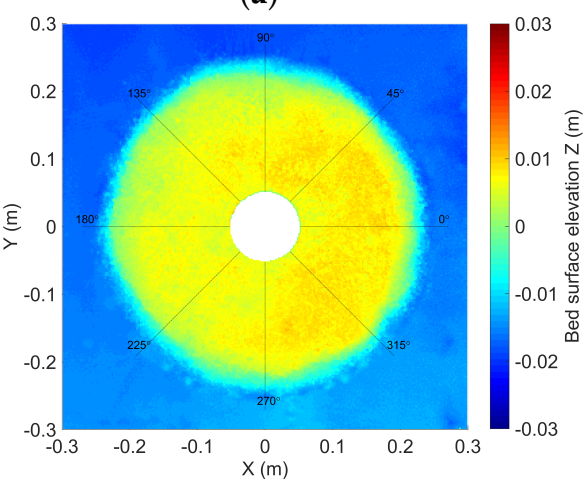

(c)

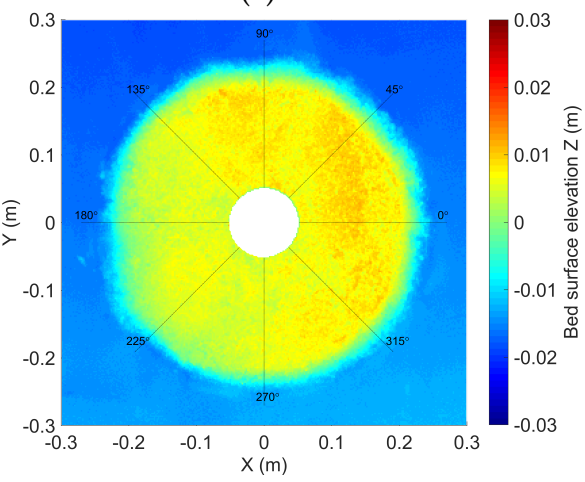

(e)

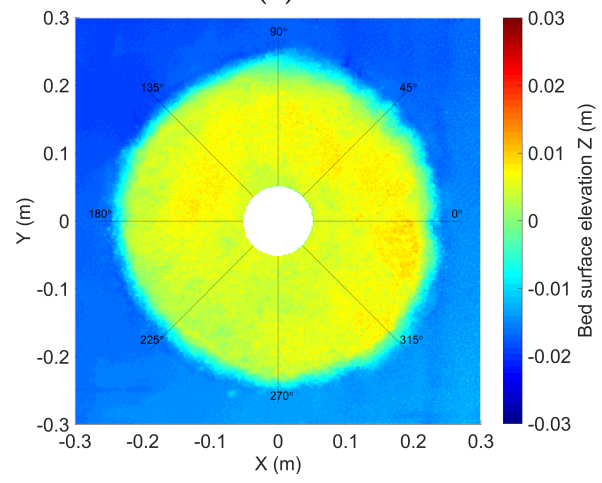

(g)

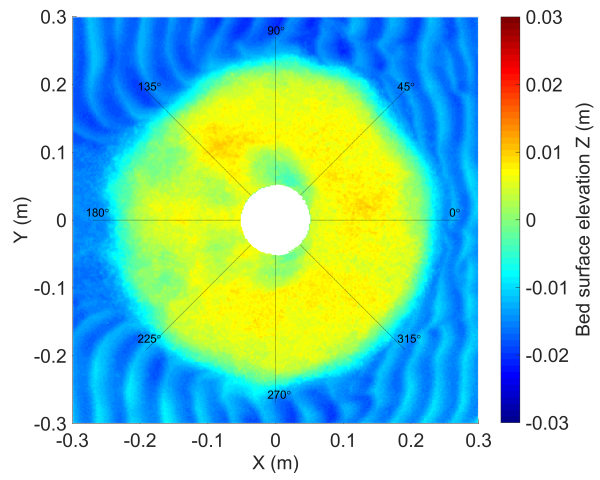

(b)

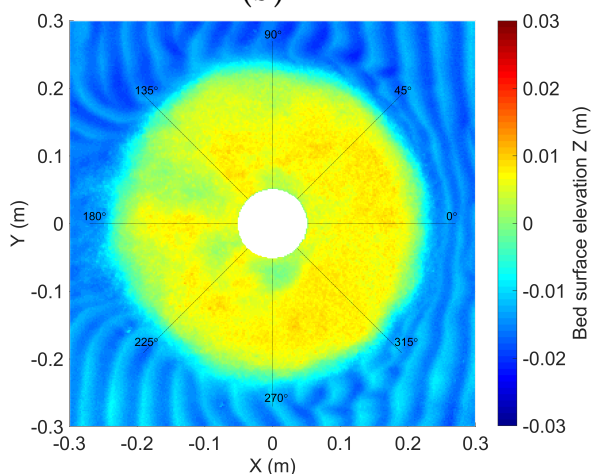

(d)



(f)

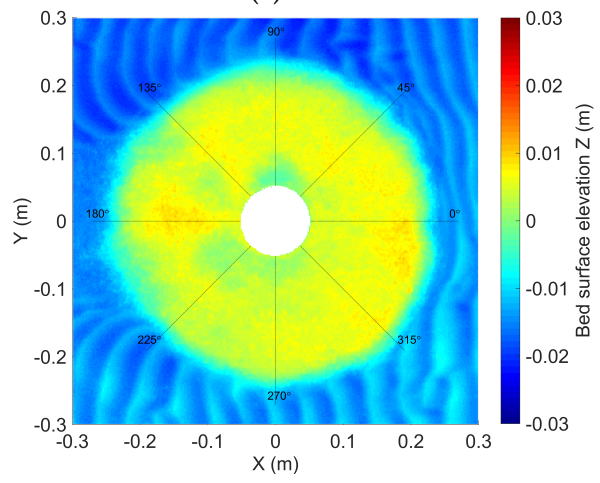

(h)

Figure 12. Cont. 




(i)

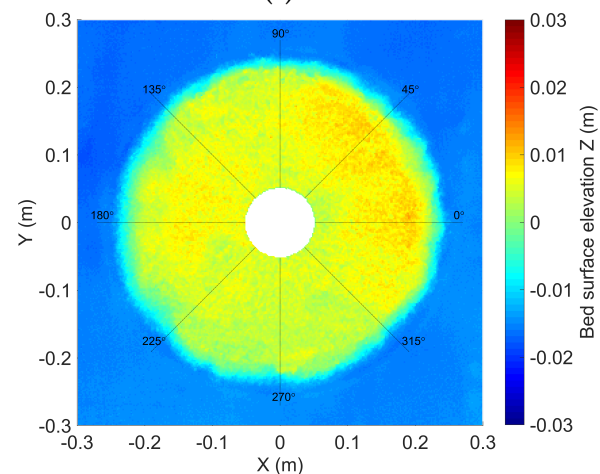

$(\mathbf{k})$

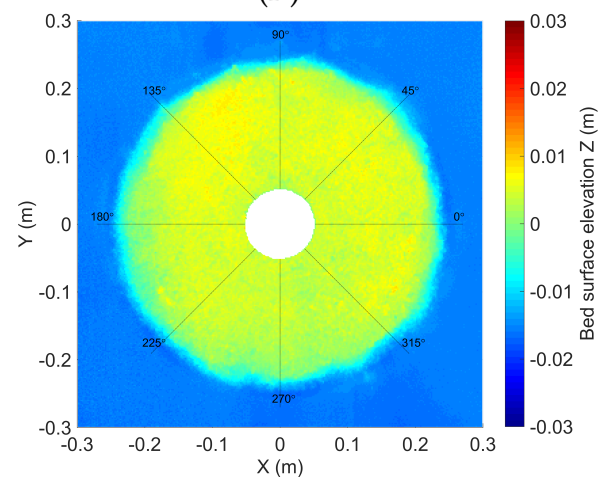

$(\mathbf{m})$

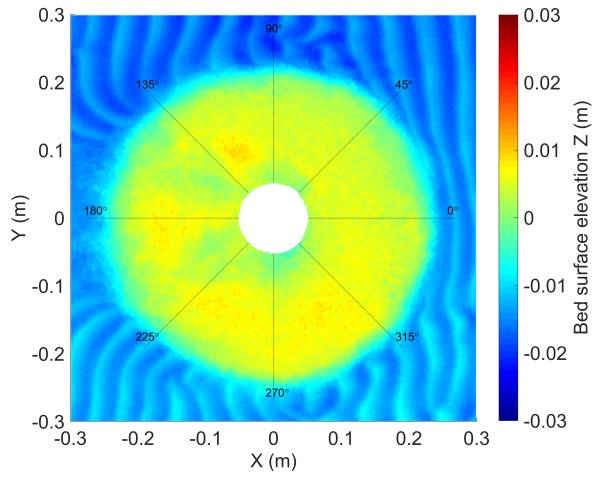

(j)

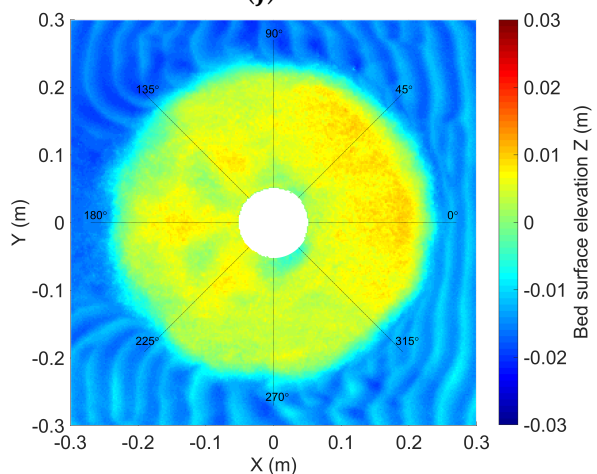

(1)

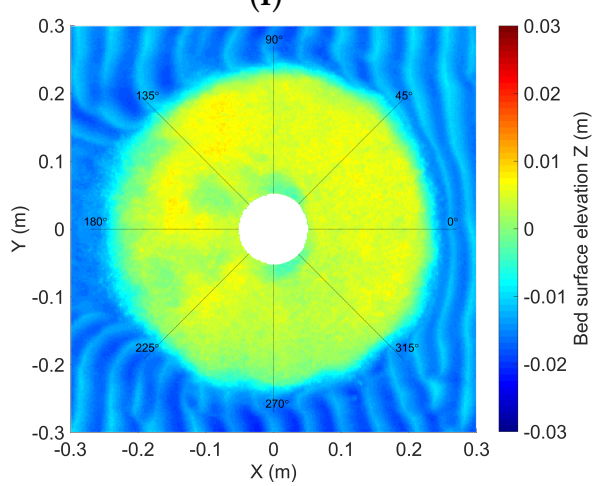

$(\mathbf{n})$

Figure 12. Initial and end profiles of TG2: (a) TG2_1 initial profile; (b) TG2_1 end profile; (c) TG2_2 initial profile; (d) TG2_2 end profile; (e) TG2_3 initial profile; (f) TG2_3 end profile; (g) TG2_4 initial profile; (h) TG2_4 end profile; (i) TG2_5 initial profile; (j) TG2_5 end profile; (k) TG2_6 initial profile; (1) TG2_6 end profile; (m) TG2_7 initial profile; (n) TG2_7 end profile. The Cartesian system presented in Figure 9 is employed.

\subsection{Model Effects Analysis}

As pure visual assessment is difficult to highlight the subtle differences of the repeated tests, quantitative analysis of the measured global damage results is essential for the discussion of model effects. Firstly, the measured global damage numbers are calculated with Equation (12) and are listed in Table 8. For TG1, the mean of $S_{3 D}$ is $\overline{S_{3 D}}=1.208$ and the standard deviation of $S_{3 D}$ is $\sigma\left(S_{3 D}\right)=0.125$. The standard deviation of the mean $\sigma\left(\overline{S_{3 D}}\right)=0.047$. For TG2, $\overline{S_{3 D}}=1.269, \sigma\left(S_{3 D}\right)=0.257$ and $\sigma\left(\overline{S_{3 D}}\right)=0.097$. Though the $S_{3 D}$ result exhibits a satisfactory repeatability in terms of both $S_{3 D}$ and $\overline{S_{3 D}}$, it should be noted that the maximum damages happen in different subareas (subareas 1, 3 and 6). Here, subareas 1 and 3 are located in the inner ring and subarea 6 is located in the current downstream side and in the second ring (see Figure 9). Despite the asymmetrical pattern of the armour damage around the pile that causes that the maximum $S_{3 D, i}$ is located alternatively between subarea 1 and subarea 3 , one can observe that the maximum damage does not necessarily occur close to the pile but possibly meters far in the prototype scenario. 


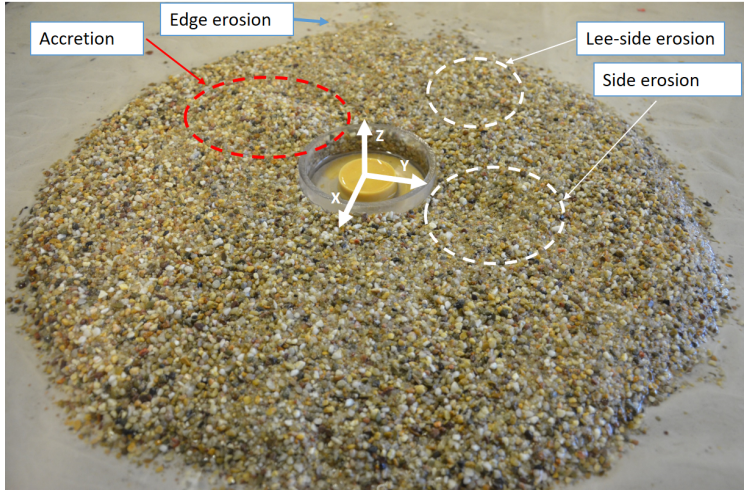

(a)

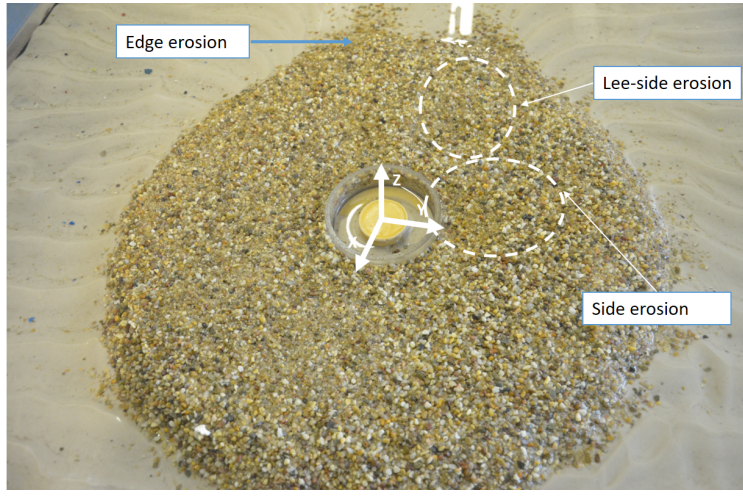

(b)

Figure 13. Photo visualisation of erosion and accretion areas in the end profiles: (a) TG1_4 end state; (b) TG2_4 end state.

Table 8. Damage numbers of the scour protection armour layer and associated subarea of where the maximum erosion is located.

\begin{tabular}{cccccc}
\hline Test ID & $S_{3 D}$ & Max $S_{3 D, i}$ in Subarea $i$ & Test ID & $S_{3 D}$ & Max $S_{3 D, i}$ in Subarea $i$ \\
\hline TG1_1 & 1.382 & 1 & TG2_1 & 1.628 & 3 \\
TG1_2 & 1.250 & 6 & TG2_2 & 1.317 & 3 \\
TG1_3 & 1.241 & 3 & TG2_3 & 1.540 & 1 \\
TG1_4 & 1.173 & 1 & TG2_4 & 1.140 & 1 \\
TG1_5 & 1.304 & 3 & TG2_5 & 1.196 & 6 \\
TG1_6 & 1.020 & 6 & TG2_6 & 1.196 & 3 \\
TG1_7 & 1.087 & 6 & TG2_7 & 0.865 & 3 \\
\hline
\end{tabular}

Assuming the damage in each subarea follows a normal distribution, the $95 \%$ confidence interval of the subarea damage $S_{3 D, i}$ is $\left[\overline{S_{3 D, i}}-2 \sigma\left(S_{3 D, i}\right), \overline{S_{3 D, i}}+2 \sigma\left(S_{3 D, i}\right)\right]$. A narrow range of the $95 \%$ confidence interval of $S_{3 D, i}$ indicates a good repeatability of the scour protection armour layer damage and a low uncertainty level. In Figure 14, the damage numbers in subareas 1 to 15 and the corresponding 95\% confidence intervals for TG1 and TG2 are plotted. The results show that the uncertainty level of the local damage strongly depends on the mean subarea damage number $\overline{S_{3 D, i}}$. Referring to Figure 9, the subareas which are located in the current incoming side have both low $\overline{S_{3 D, i}}$ and uncertainty level $\sigma\left(S_{3 D, i}\right)$. For subareas $1,3,6$ and 12 , the local damage level is high, correspondingly, $\sigma\left(S_{3 D, i}\right)$ is significantly higher. The relationships between $\overline{S_{3 D, i}}$ and $\sigma\left(S_{3 D, i}\right)$ are visualized in Figure 15. As references, the standard deviations of $S_{3 D, i}$ due to measurement and the standard deviations of global damage number $S_{3 D}$ in each test group are provided. Clearly, compared with the uncertainty due to measurement and the uncertainty of global $S_{3 D}$, the subarea damage numbers $S_{3 D, i}$ show a much higher uncertainty level. The maximum $\sigma\left(S_{3 D, i}\right)$ is up to 0.42 , which is 1.6 times of $\sigma\left(S_{3 D}\right)$. In terms of the local damage, the results obtained in the small scale test are hardly repeatable, which show strong model effects that are inherent in such experiments. 


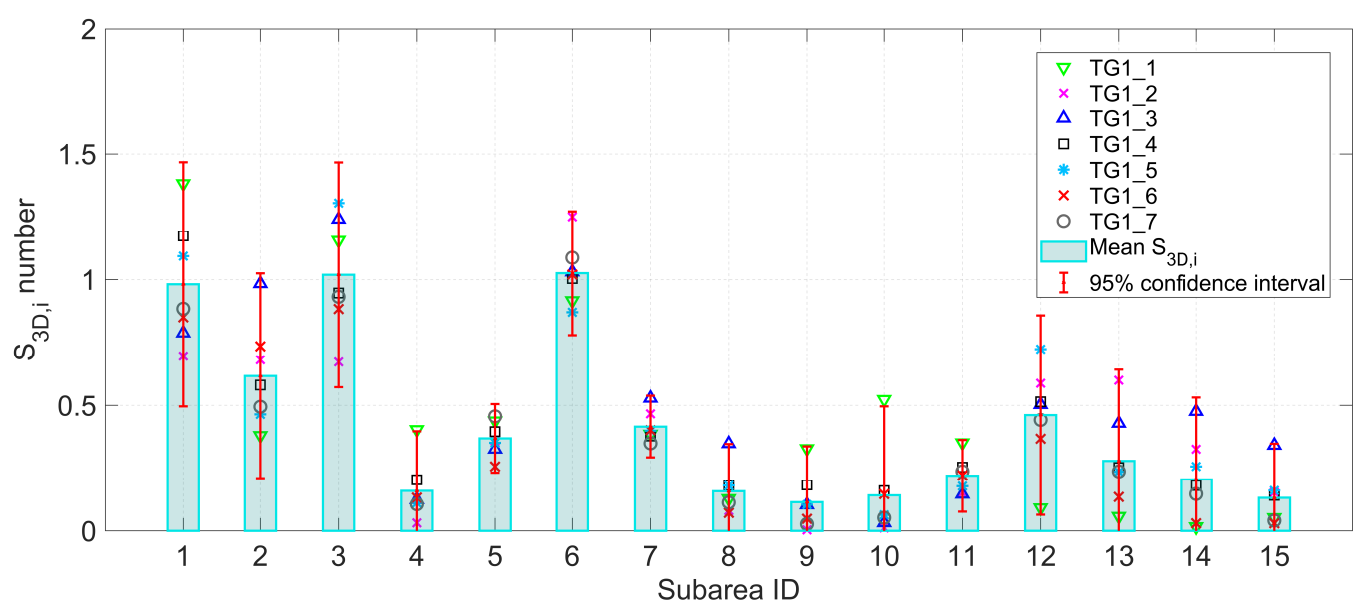

(a)

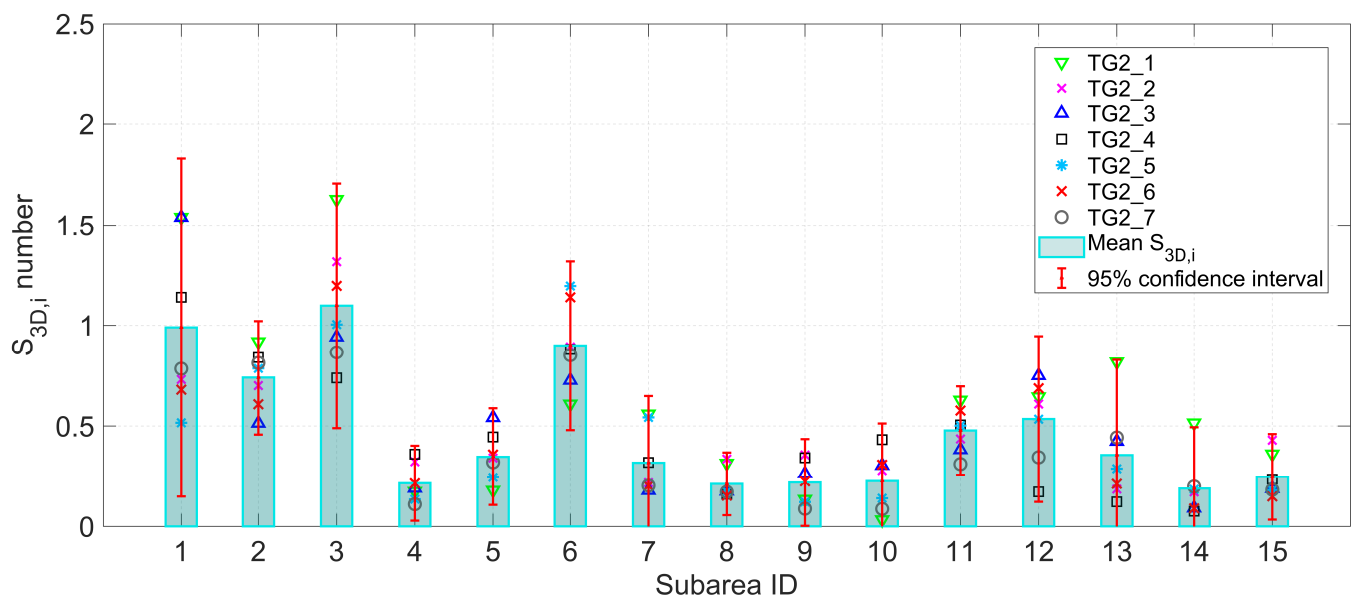

(b)

Figure 14. Damage numbers in each subarea along with the $95 \%$ confidence interval: (a) TG1; (b) TG2.



Figure 15. Relationship between the mean subarea damage $\overline{S_{3 D, i}}$ and the standard deviation $\sigma\left(S_{3 D, i}\right)$.

\section{Discussion}

An overview of the expressions of model effects for both the model inputs and outputs (global and subarea damage numbers) is listed in Table 9. For TG1, the ratio between the standard deviation of the global damage and its mean is $\sigma\left(S_{3 D}\right) / \overline{S_{3 D}}=10.3 \%$, which is 
comparable to those obtained from statistical analysis of the repeated tests given in [16] (see Table 10), where $\sigma\left(S_{3 D}\right) / \overline{S_{3 D}} \approx 11 \%$. For TG2, the standard deviation of the global damage, $\sigma\left(S_{3 D}\right)$, is up to $20.3 \% \cdot \overline{S_{3 D}}$. The $\sigma\left(S_{3 D}\right) / \overline{S_{3 D}}$ value is larger than those from [16], which is mainly due to the limited number of repeated tests in the study of [16]. The standard deviation of the local damage is even higher, where $\sigma\left(S_{3 D, i}\right)=33.1 \% \cdot \overline{S_{3 D}}$. As the physics of sediment transport under wave and current contains various stochastic processes due to the presence of waves, turbulence and non-uniformly distributed sediment particles, considerably high uncertainty level and significant model effects are inevitable as a result of (1) non-repeatability of instantaneous flow field velocity distribution and (2) non-repeatability of shape, orientation and distribution of the armour stones. This leads us to a further discussion of the possible sources of uncertainties and ways to reduce the model effects.

Table 9. Summary of expression of model effects.

\begin{tabular}{ccccccccccc}
\hline & $\overline{S_{3 D}}$ & $\sigma\left(S_{3 D}\right)$ & $\frac{\sigma\left(U_{c}\right)}{\overline{U_{c}}}$ & $\frac{\sigma\left(H_{s}\right)}{\overline{H_{s}}}$ & $\frac{\sigma\left(H_{\max }\right)}{\overline{H_{\max }}}$ & $\frac{\sigma\left(T_{p}\right)}{\overline{T_{p}}}$ & $\frac{\sigma\left(t_{a}\right)}{\overline{t_{a}}}$ & $\frac{\sigma(F)}{\bar{F}}$ & $\frac{\sigma\left(S_{3 D}\right)}{\overline{S_{3 D}}}$ & $\frac{\max \left[\sigma\left(S_{3 D, i}\right)\right]}{\overline{S_{3 D}}}$ \\
\hline TG1 & 1.208 & 0.125 & $1.3 \%$ & $1.1 \%$ & $11.6 \%$ & $1.4 \%$ & $3.5 \%$ & $20.2 \%$ & $10.3 \%$ & $19.9 \%$ \\
TG2 & 1.269 & 0.257 & $0.9 \%$ & $1.2 \%$ & $9.2 \%$ & $1.4 \%$ & $3.3 \%$ & $10.7 \%$ & $20.3 \%$ & $33.1 \%$ \\
\hline
\end{tabular}

Table 10. $S_{3 D}$ and $\sigma\left(S_{3 D}\right) / \overline{S_{3 D}}$ results from repeated tests in De Vos et al. (2012) [16].

\begin{tabular}{ccc}
\hline & $S_{3 D}$ of Test no. 15 in [16] & $S_{3 D}$ of Test no. 20 in [16] \\
\hline Repeat 1 & 0.37 & 1.84 \\
Repeat 2 & 0.31 & 1.53 \\
Repeat 3 & 0.38 & 1.55 \\
$\sigma\left(S_{3 D}\right) / \overline{S_{3 D}}$ & $10.7 \%$ & $10.6 \%$ \\
\hline
\end{tabular}

- Incoming waves and current.

Under the conditions of the same wave spectra parameters, the model effects from the same and distinct wave trains are negligible. Referring to the measured wave conditions (Table 4) and the damage results (Table 8), the same wave train cases (TG1_1 to TG1_3, TG2_1 to TG2_3) can neither contribute to a same global damage nor a same subarea damage, indicating that the influence of same or distinct wave trains on the armour layer dynamic stability is weak. As discussed in Section 2.4, the measured wave spectra and wave height exceeding probabilities are not sensitive to the randomness of a specific wave train, except for the maximum wave height $H_{\max }$. As listed in Table 9, the relative standard deviations, $\sigma\left(H_{\max }\right) / \overline{H_{\max }}$ are $11.6 \%$ for TG1 and $9.2 \%$ for TG2, which indicates that $\sigma\left(H_{\max }\right) / \overline{H_{\max }}$ could be a major contributor to $\sigma\left(S_{3 D}\right) / \overline{S_{3 D}}$ compared to other wave parameters. The relationship between recorded $H_{\max }$ and $S_{3 D}$ is plotted in Figure 16. The fitted trend lines show that higher $H_{\max }$ could give rise to higher $S_{3 D}$ number, which is reasonable as higher $H_{\text {max }}$ introduces larger wave bottom orbital velocity acting on the armour stones. However, the correlation for the two fitted lines are weak $\left(R^{2}<0.52\right)$. Despite $H_{\text {max }}$, no clear evidence in this study can prove the links between the low uncertainty level of other measured wave parameters and the high uncertainty of local scour protection damage. For the incoming current, the uncertainty levels of depth-averaged current velocity and turbulence intensity weakly affect the uncertainty of local damage.

- $\quad$ Thickness $\left(t_{a}\right)$ and flatness $(F)$ of the armour layer.

The uncertainty due to the flatness of the armour layer is the highest among the discussed model inputs. Understandably, it contributes to high uncertainty of damage outputs. Reducing the $F$ value and the uncertainty of the $F$ value is beneficial for lowering the model effects. This may be achieved by using moulds to build the armour layer or via machine aided model construction instead of less accurate handwork in 
laboratory. In real engineering, it is impossible to build ideally flat armour layers in a wind farm. Therefore, conservatively, at least $\sigma\left(S_{3 D}\right)=20 \% \overline{S_{3 D}}$ is suggested to be considered when designing a monopile scour protection made up with multiple layers of small grains. However, it can be seen that $\sigma(F) / \bar{F}$ is lower for TG2, but the $\sigma\left(S_{3 D}\right) / \overline{S_{3 D}}$ in TG2 is higher than in TG1. This results in less evidence that the $\sigma\left(S_{3 D}\right) / \overline{S_{3 D}}$ is strongly dependent on the flatness of the armour layer.

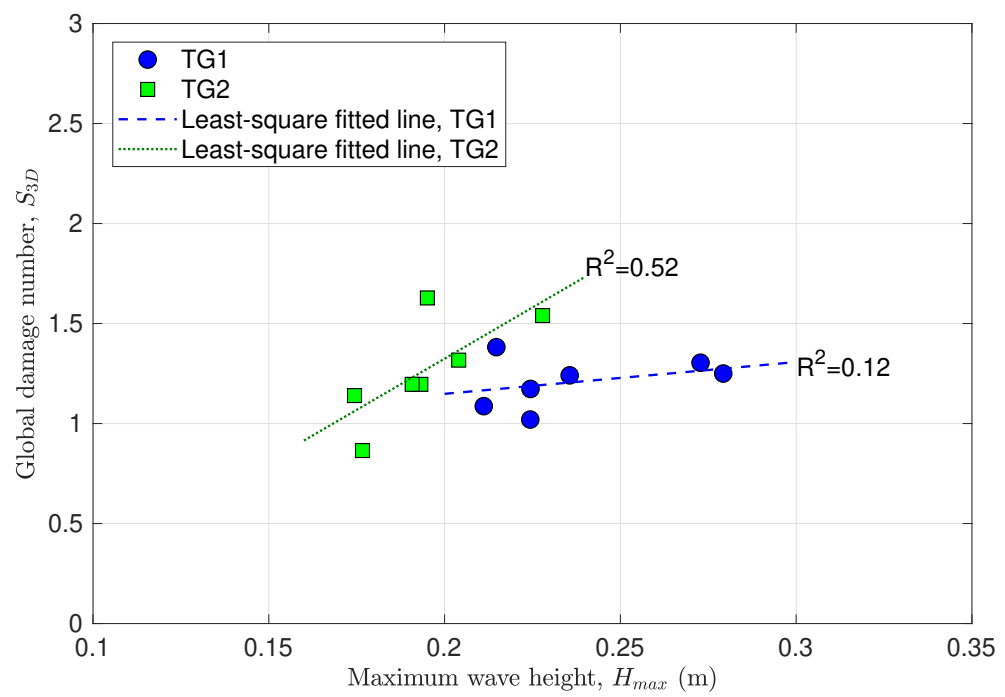

Figure 16. Relationship between maximum wave height $H_{\max }$ and global damage number $S_{3 D}$.

Despite the uncertainty of wave and current conditions around the model for each test as well as the armour layer model construction, the uncertainty level of global or subarea damage are closely associated with the expected damage level. Taking an ideal situation where the scour protection is static, the uncertainty of $S_{3 D}$ will only be attributed to the measurement uncertainty. When a high wave or high current condition is applied, the vortexes and flow field around the pile can be more chaotic, which will eventually lead to both high damage and high uncertainty of damage. Similar conclusions are also found in [49].

\section{Conclusions}

This manuscript introduces a series of repeated tests of monopile scour protection conducted in small scale wave flume using combined wave and current loadings and live-bed scour conditions. The work described in this paper has quantitatively analysed the measurement and model effects regarding erosion damage in monopile scour protection experiments. This manuscript presents the following key conclusions.

- Measurement effects due to the application of the handheld laser scanner contributes limited to the total uncertainty, the standard deviation of the global damage number is $\sigma\left(S_{3 D}\right)=0.039$ for five repeated measurements. The maximum difference of $S_{3 D}$ among the measurements is 0.095. The maximum standard deviation of the subarea damage number is $\sigma\left(S_{3 D, i}\right)=0.083$. The results show a limited impact from measurement effects to the total uncertainty.

- The model effects are analysed by means of two groups of repeated tests. In the two test groups, the wave and current conditions are well replicated as listed in Table 9. The damage profiles have shown a repeatable damage distribution. The standard deviation of the global damage number is up to $\sigma\left(S_{3 D}\right)=0.257$ and $\sigma\left(S_{3 D}\right)=20.3 \% \cdot \overline{S_{3 D}}$. The standard deviation of the subarea damage number $\sigma\left(S_{3 D, i}\right)$ reaches even larger values of $\sigma\left(S_{3 D, i}\right)=0.42$ and $\sigma\left(S_{3 D, i}\right)=33.1 \% \cdot \overline{S_{3 D}}$. The low repeatability of the maximum wave height $H_{\max }$ and the flatness of the armour layer thickness due to the irregular armour stones distribution are two important sources of the total uncertainty. The 
irreproducible and chaotic flow field around the pile is considered to be the key reason for the large standard deviation of scour protection damage number. As for the future design, a standard deviation $\sigma\left(S_{3 D}\right)$ up to $20 \% S_{3 D}$ is conservatively expected regarding a dynamically stable monopile scour protection made up with multiple layers of small grains.

The obtained results on measurement effects and model effects provides a valid data support for the future work on the analysis of scale effects that exist between small and large scale experiments of monopile scour protection erosion. The standard deviation of the armour layer damage can be applied to the design of a dynamically stable monopile scour protection considering a reasonably sufficient safety margin. The achieved data can also form the basis in the development of other novel design methodologies for monopile scour protection, e.g., the reliability based design considering the whole life cycle of OWT [50]. In the meantime, it should be addressed that the results may be limited to the dynamically stable scour protection with multiple layer small grains and the specific wave and current conditions. More investigations are anticipated for other environmental conditions and other scour protection configurations.

Author Contributions: Conceptualization, P.T., V.S. and L.D.V.; methodology, P.T., V.S., M.W., C.E.A.C., L.D.V. and M.S.; software, M.W. and M.S.; validation, M.W. and M.S.; formal analysis, M.W. and M.S.; investigation, M.W.; writing—original draft preparation, M.W.; writing—review and editing, V.S., L.D.V. and C.E.A.C.; visualization, M.W. and M.S.; supervision, P.T. and V.S.; project administration, P.T. and V.S.; funding acquisition, P.T. and V.S. All authors have read and agreed to the published version of the manuscript.

Funding: This research was funded by Special Research Funds (BOF) of Ghent University.

Institutional Review Board Statement: Not applicable.

Informed Consent Statement: Not applicable.

Acknowledgments: The authors would thank the technician team of the Coastal Engineering Research Group at UGent for the help of model construction and testing system installation.

Conflicts of Interest: The authors declare no conflict of interest.

\section{Abbreviations}

The following abbreviations are used in this manuscript:

$\begin{array}{ll}\text { ADV } & \text { Acoustic Doppler Velocimeter } \\ \text { OWT } & \text { Offshore Wind Turbine } \\ \text { TG } & \text { Test Group } \\ \text { UGent } & \text { Ghent University } \\ \text { WG } & \text { Wave Gauge }\end{array}$

\section{References}

1. Wind Europe. Offshore Wind in Europe, Trends and Statistics 2019. 2019. Available online: https://windeurope.org/aboutwind/statistics/european/wind-energy-in-europe-in-2019/ (accessed on 21 May 2021).

2. Esteban, M.D.; López-Gutiérrez, J.S.; Negro, V.; Sanz, L. Riprap scour protection for monopiles in offshore wind farms. J. Mar. Sci. Eng. 2019, 7, 440. [CrossRef]

3. Corvaro, S.; Marini, F.; Mancinelli, A.; Lorenzoni, C. Scour protection around a single slender pile exposed to waves. Coast. Eng. Proc. 2018, 1, 6. [CrossRef]

4. Tafarojnoruz, A.; Gaudio, R.; Calomino, F. Evaluation of flow-altering countermeasures against bridge pier scour. J. Hydraul. Eng. 2012, 138, 297-305. [CrossRef]

5. Pandey, M.; Azamathulla, H.M.; Chaudhuri, S.; Pu, J.H.; Pourshahbaz, H. Reduction of time-dependent scour around piers using collars. Ocean Eng. 2020, 213, 107692. [CrossRef]

6. Yang, B.; Wei, K.; Yang, W.; Li, T.; Qin, B. A feasibility study of reducing scour around monopile foundation using a tidal current turbine. Ocean Eng. 2021, 220, 108396. [CrossRef]

7. Hjorth, P. Studies on the Nature of Local Scour; Bulletin Series A; Lund Institute of Technology/Lund University, Department of Water Resources Engineering: Lund, Sweden, 1975; Volume 46. 
8. Breusers, H.N.C.; Nicollet, G.; Shen, H.W. Local Scour Around Cylindrical Piers. J. Hydraul. Res. 1977, 15, 211-252. [CrossRef]

9. Raudkivi, A.J.; Ettema, R. Clear-water scour at cylindrical piers. J. Hydraul. Eng. 1983, 109, 338-350. [CrossRef]

10. Chiew, Y.M. Mechanics of riprap failure at bridge piers. J. Hydraul. Eng 1995, 121, 635-643. [CrossRef]

11. Lauchlan, C.S.; Melville, B.W. Riprap protection at brdige piers. J. Hydraul. Eng. 2001, 127, 412-418. [CrossRef]

12. Sumer, B.M.; Fredsøe, J. The Mechanics of Scour in the Marine Environment; Advanced Series on Ocean Engineering; World Scientific: Singapore, 2002; Volume 17.

13. Det Norske Veritas AS (DNV). Design of Offshore Wind Turbine Structures; Offshore Standard DNV-OS-J101; Det Norske Veritas AS (DNV): Hovik, Norway, 2014.

14. Den Boon, J.H.; Sutherland, J.; Whitehouse, R.J.S.; Soulsby, R.; Stam, C.J.M.; Verhoeven, K.; Høgedal, M.; Hald, T. Scour behavior and scour protection for monopile foundations of offshore wind turbines. In Proceedings of the European Wind Energy Conference (EWEC), London, UK, 22-25 November 2004.

15. De Vos, L.; De Rouck, J.; Troch, P.; Frigaard, P. Empirical design of scour protections around monopile foundations Part 1: Static approach. Coast. Eng. 2011, 58, 540-553. [CrossRef]

16. De Vos, L.; De Rouck, J.; Troch, P.; Frigaard, P. Empirical design of scour protections around monopile foundations Part 2: Dynamic approach. Coast. Eng. 2012, 60, 286-298. [CrossRef]

17. Whitehouse, R.J.S.; Brown, A.; Audenaert, S.; Bolle, A.; de Schoesitter, P.; Haerens, P.; Baelus, L.; Troch, P.; das Neves, L.; Ferradosa, T.; et al. Optimising scour protection stability at offshore foundation. In Proceedings of the 7th International Conference on Scour and Erosion (ICSE-7), Perth, Australia, 2-4 December 2014.

18. De Schoesitter, P.; Audenaert, S.; Baelus, L.; Bolle, A.; Brown, A.; Das Neves, L.; Ferradosa, T.; Haerens, P.T.; Pinto, F.; Troch, P.; et al. Feasibility of a dynamically stable rock armour layer scour protection for offshore wind farms. In Proceedings of the 33rd International Conference on Ocean, Offshore and Arctic Engineering (OMAE), San Francisco, CA, USA, 8-13 June 2014.

19. Riezebos, H.; Raaijmakers, T.; Tönnies-Lohmann, A.; Waßmuth, S.; Van Steijn, P. Scour protection design in highly morphodynamic environments. In Proceedings of the 8th International Conference on Scour and Erosion (ICSE-8), Oxford, UK, 12-15 September 2016.

20. Arboleda Chavez, C.E.; Stratigaki, V.; Wu, M.; Troch, P.; Schendel, A.; Welzel, M.; Villanueva, R.; Schlurmann, T.; De Vos, L.; Kisacik, D.; et al. Large-scale experiments to improve monopile scour protection design adapted to climate change-the PROTEUS project. Energies 2019, 12, 1709. [CrossRef]

21. Nielsen, A.W.; Petersen, T.U. Stability of cover stones around a vertical cylinder under the influence of waves and current. Coast. Eng. 2019, 154, 103563. [CrossRef]

22. Wu, M.; De Vos, L.; Arboleda Chavez, C.E.; Stratigaki, V.; Fazeres-Ferradosa, T.; Rosa-Santos, P.; Taveira-Pinto, F.; Troch, P. Large scale experimental study of the scour protection damage around a monopile foundation under combined wave and current conditions. J. Mar. Sci. Eng. 2020, 8, 417. [CrossRef]

23. Sumer, B.M.; Nielsen, A.W. Sinking failure of scour protection at wind turbine foundation. PI Civil Eng. Energy 2013, 166, 170-188. [CrossRef]

24. Nielsen, A.W.; Probst, T.; Petersen, T.U.; Sumer, B.M. Sinking of armour layer around a vertical cylinder exposed to waves and current. Coast. Eng. 2015, 100, 58-66. [CrossRef]

25. Nielsen, A.W.; Petersen, T.U. Onset of motion of sediment underneath scour protection around a monopile. J. Mar. Sci. Eng. 2018, 6, 100. [CrossRef]

26. Petersen, T.U.; Sumer, B.M.; Fredsøe, J.; Raaijmakers, T.; Schouten, J.J. Edge scour at scour protections around piles in the marine environment-Laboratory and field investigation. Coast. Eng. 2015, 106, 42-72. [CrossRef]

27. Raaijmakers, T.C.; van Oeveren, M.C.; Rudolph, D.; Leenders, V.; Sinjou, W.C.P. Field performance of scour protection around offshore monopiles. In Proceedings of the 5th International Conference on Scour and Erosion (ICSE-5), San Francisco, CA, USA, 7-10 November 2010.

28. Fazares-Ferradosa, T.; Wezel, M.; Schendel, A.; Baelus, L.; Rosa Santos, P. Extended characterization of damage in rubble mound scour protection. Coast. Eng. 2020, 158, 103671. [CrossRef]

29. Baykal, C.; Sumer, B.M.; Fuhrman, D.R.; Jacobsen, N.G.; Fredsøe, J. Numerical simulation of scour and backfilling processes around a circular pile in waves. Coast. Eng. 2017, 122, 87-107. [CrossRef]

30. Schendel, A.; Hildebrandt, A.; Schlurmann, T. Experimental study on the progression of scour around a monopile in unidirectional and tidal currents. In Proceedings of the 6th International Conference on the Application of Physical Modelling in Coastal and Port Engineering and Science, Ottawa, ON, Canada, 10-13 May 2016.

31. Mayall, R.O.; McAdam, R.A.; Whitehouse, R.J.S.; Burd, H.J.; Byrne, B.W.; Heald, S.G.; Sheil, B.B.; Slater, P.L. Flume tank testing of offshore wind turbine dynamics with foundation scour and scour protection. J. Waterw. Port Coast. Ocean Eng. 2020, 146, 04020033. [CrossRef]

32. Kortenhaus, A.; Van der Meer, J.; Burcharth, H.F.; Geeraerts, J.; Pullen, T.; Ingram, D.; Troch, P. D40 Report on Conclusions of Scale Effects, Workpackage 7, Quantification of Measurement Errors, Model and Scale Effects Related to Wave Overtopping; Leichtweiß-Institute for Hydraulic Engineering: Braunschweig, Germany, 2005.

33. Qiu, W.; Junior, J.S.; Lee, D.; Lie, H.; Magarovskii, V.; Mikami, T.; Rousset, J.M.; Sphaier, S.; Tao, L.; Wang, X. Uncertainties related to predictions of loads and responses for ocean and offshore structures. Ocean Eng. 2014, 86, 58-67. [CrossRef] 
34. Wahlin, B.; Wahl, T.; Gonzalez-Castro, J.A.; Fulford, J.; Robeson, M. Task committee on experimental uncertainty and measurement errors in hydraulic engineering: An update. In Proceedings of the World Water and Environmental Resources Congress 2005: Impacts of Global Climate Change (EWRI), Anchorage, AK, USA, 15-19 May 2005.

35. De Vos, L. Optimisation of Scour Protection Design for Monopiles and Quantification of Wave Run-Up. Ph.D. Thesis, Ghent University, Ghent, Belgium, 2008.

36. Debaveye, R.; De Riemacker, B. Data Analysis of the 3D Damage Number in Small-Scale Monopile Scour Protection Experiments. Master's Thesis, Ghent University, Ghent, Belgium, 2020.

37. Ettema, R.; Melville, B.W.; Barkdoll, B. Scale effect in pier-scour experiments. J. Hydraul. Eng. 1996, 124, 639-642. [CrossRef]

38. Heller, V. Scale effects in physical hydraulic engineering models. J. Hydraul. Res. 2011, 49, 293-306. [CrossRef]

39. Hughes, S.A. Physical Models and Laboratory Techniques in Coastal Engineering; Advanced Series on Ocean Engineering; World Scientific: Singapore, 1993; Volume 7.

40. Reis, M.T.; Neves, M.G.; Hedges, T. Investigating the lengths of scale model tests to determine mean wave overtopping discharges. J. Hydraul. Res. 2008, 50, 441-462. [CrossRef]

41. Williams, H.E.; Briganti, R.; Romano, A.; Dodd, N. Experimental Analysis of Wave Overtopping: A new small scale laboratory dataset for the assessment of uncertainty for smooth sloped and vertical coastal structures. J. Mar. Sci. Eng. 2019, 7, 217. [CrossRef]

42. Ghent University. Large Physical Wave Flume. 2020. Available online: https://www.ugent.be/ea/civil-engineering/en/ research/coastal-bridges-roads/coastal-engineering/infrastructure-services/overview (accessed on 21 May 2021).

43. Nortek Group. Nortek Quick Guide-Vectrino Profiler. 2017. Available online: https:/ /www.nortekgroup.com/assets/software/ N3015-012-NQG_VECTRINPROO_1017.pdf (accessed on 21 May 2021).

44. Oumeraci, H. Scour in front of vertical breakwaters-Review of problems. In Proceeding of the International Workshop on Wave Barriers in Deepwaters (PHRI), Yokosuka, Japan, 10-14 January 1994; pp. 281-317.

45. Van Rijn, L.C. Sediment transport, part II: Suspended load transport. J. Hydraul. Eng. 1984, 110, 1613-1641. [CrossRef]

46. FARO ${ }^{\circledR}$ Technologies Inc. Freestyle3D and Software User Manual. 2017. Available online: https://faro.app.box.com/s/ pkfiiyeom0kwx722cff4yh01lwyspxu2/file/314135742270 (accessed on 21 May 2021).

47. JCGM. JCGM 100:2008 Evaluation of Measurement Data-Guide to the Expression of Uncertainty in Measurement (GUM). 2008. Available online: https://www.bipm.org/documents/20126/2071204/JCGM_100_2008_E.pdf/cb0ef43f-baa5-11cf-3f85-4dcd8 $6 f 77 b d 6$ (accessed on 21 May 2021).

48. Richard, J.-B.; Thomson, J.; Polagye, B.; Bard, J. Method for identification of Doppler noise levels in turbulent flow measurements dedicated to tidal energy. Int. J. Mar. Energy 2013, 3-4, 52-64. [CrossRef]

49. Wu, M.; Arnout, J.; Molina Ruiz, J.; Arboleda Chavez, C.; Stratigaki, V.; Troch, P. Evaluation of uncertainty of damage results in experimental modelling of monopile foundation scour protection. In Proceedings of the 38rd International Conference on Ocean, Offshore and Arctic Engineering (OMAE), Glasgow, Scotland, 9-14 June 2019.

50. Fazeres-Ferradosa, T.; Taveira-Pinto, F.; Romão, X.; Vanem, E.; Reis, M.T.; das Neves, L. Probabilistic design and reliability analysis of scour protections for offshore windfarms. Eng. Fail. Anal. 2018, 91, 291-305. [CrossRef] 